OPEN ACCESS

Edited by:

Walid Alali,

Hamad Bin Khalifa University, Qatar

Reviewed by:

Francisco Diez-Gonzalez, University of Georgia, United States Issmat Kassem, American University of Beirut, Lebanon

*Correspondence: Melissa M. Kendall melissakendall@virginia.edu

Specialty section: This article was submitted to Food Microbiology,

a section of the journal Frontiers in Microbiology

Received: 13 April 2017 Accepted: 26 September 2017 Published: 12 October 2017

Citation:

Anderson CJ and Kendall MM (2017) Salmonella enterica Serovar

Typhimurium Strategies for Host Adaptation. Front. Microbiol. 8:1983. doi: 10.3389/fmicb.2017.01983

\section{Salmonella enterica Serovar Typhimurium Strategies for Host Adaptation}

\author{
Christopher J. Anderson and Melissa M. Kendall*
}

Department of Microbiology, Immunology, and Cancer Biology, University of Virginia School of Medicine, Charlottesville, VA, United States

Bacterial pathogens must sense and respond to newly encountered host environments to regulate the expression of critical virulence factors that allow for niche adaptation and successful colonization. Among bacterial pathogens, non-typhoidal serovars of Salmonella enterica, such as serovar Typhimurium (S. Tm), are a primary cause of foodborne illnesses that lead to hospitalizations and deaths worldwide. S. Tm causes acute inflammatory diarrhea that can progress to invasive systemic disease in susceptible patients. The gastrointestinal tract and intramacrophage environments are two critically important niches during $S$. Tm infection, and each presents unique challenges to limit $S$. Tm growth. The intestinal tract is home to billions of commensal microbes, termed the microbiota, which limits the amount of available nutrients for invading pathogens such as S. Tm. Therefore, S. Tm encodes strategies to manipulate the commensal population and side-step this nutritional competition. During subsequent stages of disease, S. Tm resists host immune cell mechanisms of killing. Host cells use antimicrobial peptides, acidification of vacuoles, and nutrient limitation to kill phagocytosed microbes, and yet $S$. Tm is able to subvert these defense systems. In this review, we discuss recently described molecular mechanisms that $S$. Tm uses to outcompete the resident microbiota within the gastrointestinal tract. S. Tm directly eliminates close competitors via bacterial cell-to-cell contact as well as by stimulating a host immune response to eliminate specific members of the microbiota. Additionally, S. Tm tightly regulates the expression of key virulence factors that enable S. Tm to withstand host immune defenses within macrophages. Additionally, we highlight the chemical and physical signals that $S$. Tm senses as cues to adapt to each of these environments. These strategies ultimately allow $S$. Tm to successfully adapt to these two disparate host environments. It is critical to better understand bacterial adaptation strategies because disruption of these pathways and mechanisms, especially those shared by multiple pathogens, may provide novel therapeutic intervention strategies.

Keywords: Salmonella, macrophages, signaling pathways, infection, microbiota

\section{Salmonella enterica SEROVAR TYPHIMURIUM INFECTION}

Non-typhoidal serovars of Salmonella enterica (NTS) are leading causes of foodborne illness and diarrheal disease worldwide (Graham et al., 2000; Vojdani et al., 2008; Scallan et al., 2011; Ansari et al., 2012; Kabir et al., 2012; Kozak et al., 2013). In the United States, NTS infections result in more hospitalizations and deaths compared to infections caused by any other foodborne pathogen 
(Scallan et al., 2011). Among NTS, serovar Typhimurium (S. $\mathrm{Tm}$ ) is one of the most commonly isolated from patients around the globe (Galanis et al., 2006). NTS infections typically present as a self-limiting diarrheal disease (Acheson and Hohmann, 2001; Gordon, 2008); however, NTS gastrointestinal infections can develop into systemic disease in immunocompromised patients, as well as a small subset of immunocompetent patients (Acheson and Hohmann, 2001; Gordon, 2008). Currently, there are no effective vaccines against gastrointestinal infections. Additionally, treatment options are limited because antibiotics may lead to increased levels of $S$. Tm shedding and also because $S$. Tm is developing resistance to many antibiotics (Wiström et al., 1992; Martin, 2012; Diard et al., 2014; Gopinath et al., 2014; Strugnell et al., 2014). Accordingly, alternative therapeutic intervention strategies are needed.

$S$. Tm establishes infection in the gastrointestinal tract and causes acute gastroenteritis. A common feature of $S$. Tm disease is inflammatory diarrhea indicated by the presence of neutrophils in patient stool samples (Harris et al., 1972). Type III secretion systems (T3SSs) are molecular syringe-like structures that allow Gram-negative organisms to directly inject effector proteins into the cytosol of host cells (Deng et al., 2017). S. Tm uses a T3SS encoded within Salmonella Pathogenicity Island (SPI) 1 (T3SS-1) to actively invade epithelial cells, induce inflammation, and breach the epithelial barrier (Galán and Curtiss, 1989; Tsolis et al., 1999). After exiting the intestinal tract, S. Tm is phagocytosed by resident and recruited immune cells, including macrophages. S. Tm utilizes the SPI-2 encoded T3SS (T3SS-2) to survive and replicate within these phagocytes (Hensel et al., 1995; Ochman et al., 1996; Shea et al., 1996). The cumulative effects of T3SS-2 cause unchecked bacterial replication during systemic infection and lethal disease (Yoon et al., 2009).

Decades of research has identified a vast repertoire of $S$. Tm virulence determinants (extensively reviewed in Fàbrega and Vila, 2013). Recent studies have expanded our understanding of factors that influence virulence gene expression, including growth phase and environmental signals (Kröger et al., 2013; Srikumar et al., 2015); however, less is known about the signal transduction pathways that link environmental signals to virulence gene expression. In this review, we discuss recent findings concerning strategies that $S$. Tm uses to overcome microbiota- and hostderived obstacles within the intestinal and intramacrophage environments. Additionally, we highlight signals that $S$. Tm uses to coordinate expression of virulence genes required for adaptation to these distinct environments.

\section{MAKING ROOM WITHIN THE CROWDED INTESTINAL TRACT}

The gastrointestinal tract is home to billions of microbes termed the microbiota. Interactions between the host, the microbiota, and pathogens have profound impacts on infection (YuristDoutsch et al., 2014; McKenney and Pamer, 2015; Bäumler and Sperandio, 2016; Gart et al., 2016; Kendall and Sperandio, 2016; McKenney et al., 2016). The microbiota function as a barrier to limit pathogen colonization and shedding (Endt et al., 2010), an ability collectively referred to as colonization resistance. Colonization resistance is largely attributed to the ability of the microbiota to outcompete invading pathogens for nutrients; however, the microbiota can also modulate host mucosal immune responses important for clearing infection (Endt et al., 2010; Thiemann et al., 2017). Dysbiosis, or alterations to the microbiota, creates a non-competitive niche in which S. Tm is able to establish infection and rapidly replicate in the intestine. Antibiotic use results in disruptions to the microbiota and is a key risk factor associated with the Salmonella-associated diarrhea (Acheson and Hohmann, 2001; Gordon, 2008).

Although antibiotic-related dysbiosis provides an opening for $S$. Tm to establish infection, $S$. Tm also directly perturbs the microbiota to enhance and prolong infection (Figure 1A). S. Tm relies primarily on the T3SS-1, and to an extent the T3SS-2, to induce host inflammation, and the resulting innate immune response non-specifically targets the microbiota along with $S$. Tm (Barthel et al., 2003; Coburn et al., 2005; Stecher et al., 2007; Barman et al., 2008; Lawley et al., 2008; Sekirov et al., 2008; Juricova et al., 2013; Lam and Monack, 2014; Drumo et al., 2016; Rivera-Chávez et al., 2016b). As a result of T3SS-induced inflammation, a proportion of infecting $S$. Tm cells succumb to host immune responses; however, a sufficient amount of $S$. Tm cells survive to successfully establish infection (Raffatellu et al., 2009; Liu et al., 2012; Bogomolnaya et al., 2013; Maier et al., 2014; Diaz-Ochoa et al., 2016). Several environmental conditions contribute to T3SS-1 expression (Golubeva et al., 2012). For example, oxygen limitation and high salt concentrations enhance SPI-1 expression and epithelial cell invasion (Galán and Curtiss, 1990; Lee and Falkow, 1990; Bajaj et al., 1996; Mizusaki et al., 2008), whereas bile and some long and short chain fatty acids, such as a butyrate, oleate, myristate, and palmitate, repress T3SS-1 expression (Prouty and Gunn, 2000; Lawhon et al., 2002; Gantois et al., 2006; Eade et al., 2016; Golubeva et al., 2016). The balance of activating and repressing signals is thought to enrich S. Tm invasion in the ileum in vivo (Lawhon et al., 2002; Gantois et al., 2006; Eade et al., 2016). Expression of the T3SS-1 is regulated by a feed-forward loop in which the regulatory proteins HilD, HilC, and RtsA positively control expression of the master transcription factor HilA (Bajaj et al., 1995; Ellermeier et al., 2005). HilD, HilC, and RtsA are transcription factors that bind to the hilA promoter to induce hilA expression (Schechter and Lee, 2001; Olekhnovich and Kadner, 2002; Ellermeier and Slauch, 2004). HilA then activates the expression of the remaining transcription factors and structural components of the T3SS-1, as well as non-SPI-1-encoded effectors (Phoebe Lostroh and Lee, 2001). Expression of the T3SS-1 core regulatory system is in turn regulated by accessory factors that are presumed to respond to environmental signals (Golubeva et al., 2012), but how these signals are incorporated into the SPI-1 regulatory pathway has not been fully elucidated.

Besides causing unspecific disruption to the microbiota as a whole, $S$. Tm-induced inflammation impacts particular intestinal microbes that alter concentrations of metabolites and/or host responses that would otherwise limit $S$. Tm infection (Figure 1B). For example, $S$. Tm infection induces RegIII $\beta$ expression, and $\operatorname{RegIII} \beta$ is directly bactericidal against Bacteroides sp. and 


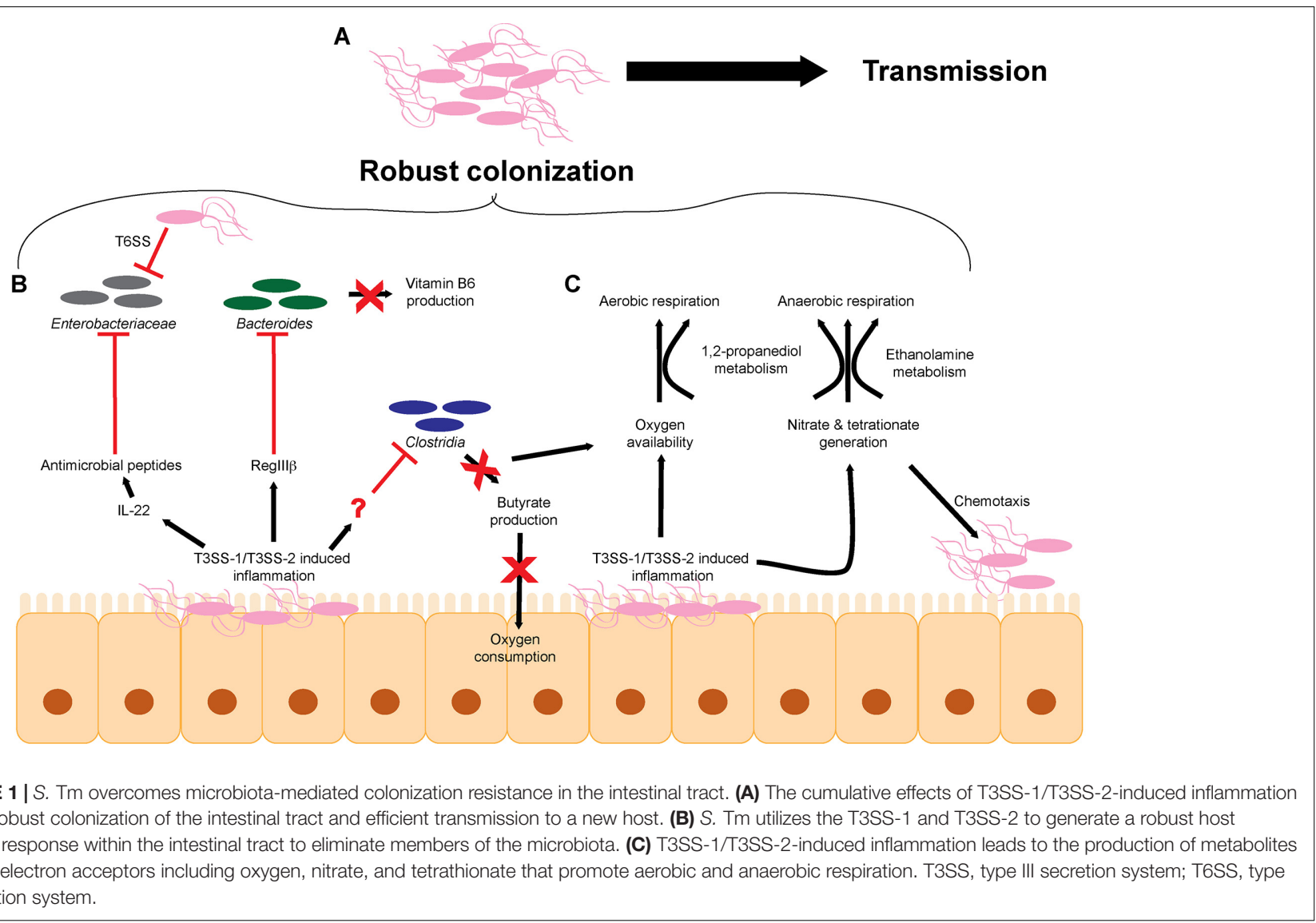

Eubacterium rectale (Miki et al., 2017). RegIII lectin family proteins are expressed in the intestinal tract and are important for maintaining intestinal homeostasis and combating pathogens (Cash et al., 2006; Vaishnava et al., 2008; Miki et al., 2012). Suppression of Bacteroides sp. is associated with changes in metabolite availability in the gut, most notably a decrease in vitamin B6 concentrations (Miki et al., 2017). Significantly, reconstitution of Bacteroides or supplementation of vitamin B6 contributes to the resolution of $S$. Tm infection, further underscoring the complex interplay of host, bacteria, and metabolites (Miki et al., 2017). S. Tm T3SS-1 and T3SS-2-induced inflammation also leads to depletion of Clostridia sp. in the intestine, which enhances $S$. Tm colonization (Rivera-Chávez et al., 2016b) (detailed in the next section). The host factor that directly depletes Clostridia sp. has not been identified.

Additionally, commensal Escherichia coli represents a minor component of the microbiota during homeostasis, but during general dysbiosis, the proportion of $E$. coli within the bacterial community increases (Winter et al., 2013). E. coli and S. Tm compete for metabolites and deploy molecules to limit growth of each other (Raffatellu et al., 2009; Deriu et al., 2013; SassoneCorsi et al., 2016). For example, iron is an essential nutrient for most microbes and is typically limited within the host; therefore, microbes have evolved mechanisms to scavenge iron (Behnsen and Raffatellu, 2016). E. coli and S. Tm produce and secrete siderophores, which are small molecules that chelate iron (Crouch et al., 2008; Behnsen and Raffatellu, 2016). E. coli siderophores can be conjugated to microcins, small antibacterial peptides that kill bacterial cells through an unknown mechanism (Rebuffat, 2012; Sassone-Corsi et al., 2016). To fight back, the S. Tm T3SS-1 and T3SS-2 promote expression of the chemokine IL-22, which results in the production of antimicrobials that kill $E$. coli but are ineffective against S. Tm (Godinez et al., 2008; Raffatellu et al., 2009; Stelter et al., 2011; Liu et al., 2012; Behnsen et al., 2014). By inducing IL-22, $S$. Tm eliminates Enterobacteriaceae species and thus direct nutritional competitors.

$S$. Tm also takes direct action against competitors using a type VI secretion system (T6SS). T6SSs are commonly found in the Proteobacteria and Bacteroidetes phyla and are structurally homologous to bacteriophage tail complexes (Bönemann et al., 2009; Russell et al., 2014; Hood et al., 2017). These dynamic structures contract to directly inject effector proteins into target cells (Basler et al., 2012). Although T6SS can inject effector proteins into host cells (Ma and Mekalanos, 2010; Schwarz et al., 2010), increasing evidence suggest that T6SSs primarily target and cause subsequent death of bacterial cells (Mougous et al., 2006; Pukatzki et al., 2006; Bingle et al., 2008; Cianfanelli et al., 2016). The T6SS encoded by $S$. Tm has selective bactericidal efficacy against commensal organisms in vitro, including other members of the Enterobacteriaceae, such as E. coli W3110, Klebsiella oxytoca, and Klebsiella variicola (Brunet et al., 2015; 
Sana et al., 2016). However, Enterobacter cloacae and E. coli JB2 are resistant to $S$. Tm T6SS attack (Sana et al., 2016). It is currently unclear why different species are susceptible or resistant. The efficacy of the $S$. Tm T6SS against $K$. oxytoca data were validated in vivo during intestinal co-infection studies (Sana et al., 2016). These data support an important role for the S. Tm T6SS against other members of the microbiota; however, the benefits of selective killing remain to be defined. A better understanding of the commensal organisms that are directly targeted by $S$. Tm via the T6SS in vivo may reveal essential metabolites that are being differentially regulated that may impact $S$. Tm growth or virulence gene expression.

Collectively, these findings reveal that a central strategy $S$. Tm uses to colonize the host is to actively displace members of the microbiota. $S$. Tm achieves this through manipulation and exploitation of host responses (Stecher et al., 2007; Mooney et al., 2015). Moreover, $S$. Tm is capable of directly eliminating particular bacterial species. This transforms the intestinal tract into an environment that $S$. Tm is optimized to survive in and ultimately lowers the barrier of colonization resistance.

\section{METABOLISM IN THE FACE OF INFLAMMATION}

Dysbiosis not only results in changes in the bacterial populations but also changes the chemistry of the intestine (Zeng et al., 2017). Hence, a second aspect of $S$. Tm infection includes exploiting nutrients generated specifically during infection. The majority of bacteria that comprise the microbiota are obligate anaerobes that rely on fermentation for growth (Gibson and Roberfroid, 1995). Enterobacteriaceae, including S. Tm, are able to gain energy by respiration. Respiration generates higher amounts of ATP compared to fermentation and thereby enables $S$. Tm to outgrow many members of the microbiota (Wiles et al., 2006; Brochier-Armanet et al., 2009; Marteyn et al., 2010; Maier et al., 2013; Ng et al., 2013; Winter et al., 2013; Zeng et al., 2017) (Figure 1C). During homeostasis, host colonocytes consume oxygen, yielding a localized environment characterized by low oxygen partial pressure (Carreau et al., 2011; Espey, 2013). Colonocytes preferentially oxidize short-chain fatty acids, such as butyrate, to respire oxygen (Hamer et al., 2008; Donohoe et al., 2012; Kelly et al., 2015). Because Clostridia are the major producers of butyrate in the intestine, depletion of Clostridia with antibiotics or during $S$. Tm infection leads to a concomitant decrease in oxygen consumption by colonocytes (Sekirov et al., 2008; Louis and Flint, 2009; Gill et al., 2012; Vital et al., 2014; Rivera-Chávez et al., 2016b). S. Tm capitalizes on newly available oxygen to rapidly grow within the intestine (Rivera-Chávez et al., 2016b). These findings reveal a complex role for oxygen during infection. On the one hand, low levels of oxygen enhance SPI-1 expression, leading to increased inflammation and subsequent restriction of commensal organisms such as Clostridia. On the other hand, newly available oxygen promotes growth within the intestine. Oxygen limitation might therefore allow $S$. Tm to regulate the kinetics of SPI-1 expression within the intestine. In this proposed model, oxygen limitation early on during infection would promote SPI-1 expression, which would then in turn deplete commensal Clostridia via the host immune response, which would then result in an increase in oxygen availability leading to $S$. Tm outgrowth and subsequent reduction in SPI-1 expression. Additionally, the decrease in butyrate availability may also restrict the abundance of butyrate metabolizing members of the microbiota leading to even greater levels of dysbiosis.

The electron acceptors nitrate and tetrathionate also support S. Tm growth during infection (Winter et al., 2010; Lopez et al., 2012, 2015). The T3SS-1-secreted effector SopE is a bacteriophage-encoded activator of host Rho GTPases that results in host cytoskeletal rearrangements and activation of immune signaling pathways (Hardt et al., 1998). Additionally, SopE induces expression of host inducible nitric oxide synthase (iNOS) and generates nitrate (Lopez et al., 2012). Tetrathionate generation is a two-step process. Microbiotaproduced hydrogen sulfide is converted by host colonocytes to thiosulfate, which reacts with oxygen radicals produced by host NADPH oxidase to generate tetrathionate (Winter et al., 2010). Tetrathionate reduction is coupled to ethanolamine, 1,2-propanediol, or fructose-asparagine oxidation (PriceCarter et al., 2001; Thiennimitr et al., 2011; Ali et al., 2014; Sabag-Daigle et al., 2016; Faber et al., 2017). Ethanolamine is a component of phosphatidylethanolamine, one of the most abundant phospholipids in host and microbial membranes (Randle et al., 1969; Dawaliby et al., 2015). The turnover of enterocytes and microbial cells as well as the diet provide a continuously replenished source of ethanolamine in the intestine (Cotton, 1972; Kawai et al., 1974; Dowhan, 1997, 2003; Snoeck et al., 2005; Bakovic et al., 2007). The accumulation of 1,2-propanediol depends primarily on the microbiota. It is thought that the ability of Bacteroides sp. to breakdown complex carbohydrates allows for the production of 1,2-propanediol as a byproduct of fermentation of methyl-pentoses (Faber et al., 2017), although experiments are needed to demonstrate this during the course of infection. This model is supported by the findings that 1,2-propanediol is nearly undetectable in germ-free mice; however, the presence of either Bacteroides fragilis or Bacteroides thetaiotaomicron is associated with 1,2-propanediol accumulation (Faber et al., 2017). Additionally, expression of $S$. Tm genes coding for 1,2-propanediol metabolism are induced in the presence of $B$. thetaiotaomicron in vivo ( $\mathrm{Ng}$ et al., 2013; Faber et al., 2017). Furthermore, the presence of B. thetaiotaomicron within the intestinal tract enhances $S$. Tm expression of additional carbohydrate metabolism and transport genes, including sialic acid and fucose catabolic pathways ( $\mathrm{Ng}$ et al., 2013). The B. thetaiotaomicron-encoded sialidase liberates sialic acid, which promotes $S$. Tm sialic acid metabolism and intestinal growth (Ng et al., 2013). These data indicate a somewhat paradoxical relationship between $S$. Tm and Bacteroides sp. As discussed above, S. Tm-induced inflammation restricts the levels of Bacteroides sp. (Miki et al., 2017) and yet Bacteroides sp. are critical for the accumulation of multiple metabolites that $S$. Tm utilizes during infection (Ng et al., 2013; Faber et al., 2017). These seemingly conflicting ideas suggest an even more complex relationship between pathogen and microbiota. Rather than presence or absence of commensals, 
S. Tm may require a fine-tuned abundance of microbes to generate beneficial metabolites without these organisms directly competing with $S$. Tm.

$S$. Tm also exploits electron acceptors as spatiotemporal cues for colonization and tissue invasion. Nitrate and tetrathionate are indirect signals for $S$. Tm chemotaxis and thereby influence subsequent stages in $S$. Tm infection (Rivera-Chavez et al., 2013). The chemotaxis proteins Aer and Tsr sense changes in redox and proton motive force during tetrathionate and nitrate respiration, respectively (Edwards et al., 2006; RiveraChávez et al., 2016a). Both Aer and Tsr promote T3SS-1/T3SS2-dependent intestinal colonization (Rivera-Chavez et al., 2013). Tsr-dependent chemotaxis correlates with localized host production of iNOS and enables $S$. Tm to invade ileal Peyer's patches (Rivera-Chávez et al., 2016a). Surprisingly, no additive effect is seen with Aer and Tsr-dependent chemotaxis (RiveraChavez et al., 2013). This suggests that these two sensing pathways may be interconnected and perhaps functionally redundant. Connectivity of these two pathways is further supported by the observation that the presence of nitrate reduces the expression of genes involved in tetrathionate respiration as well as the growth advantage conferred by tetrathionate respiration (Lopez et al., 2012). It is currently unclear how S. Tm balances the sensing and utilization of two signals that may restrict one another.

Much of our understanding of the host-microbiota-pathogen interplay has been generated through genetic manipulation of the pathogen, and alternative experimental approaches are shedding new light on this interaction. For example, defined commensal communities have been used to reconstitute the microbiota of germ-free mice and study the contributions of specific members of the microbiota necessary for effective colonization resistance (Dewhirst et al., 1999; Stecher et al., 2010; Brugiroux et al., 2016). Studies using defined microbial communities will also contribute to understanding how differences in microbial species between susceptible and resistant intestinal environments impact $S$. Tm virulence gene expression. Additionally, a recent RNA-seq study assessed gene expression in $S$. Tm grown under 22 different in vitro conditions that mimicked aspects of infection, which could reveal new signals important for controlling the expression of key metabolic and virulence determinants (Kröger et al., 2013). Future in vivo metabolomics studies may identify specific microbiota or diet-dependent molecules that impact $S$. Tm virulence gene expression and/or host response. In line with this, a high salt diet was recently identified as significantly altering the host response during $S$. Tm infection (Tubbs et al., 2017). Thus, the ability to manipulate commensal microbial communities and intestinal metabolite concentrations offers an exciting tool to further understand how microbiota and metabolites not only impact $S$. Tm growth but also impact $S$. Tm virulence.

Collectively, these findings highlight that $S$. Tm thrives during host dysbiosis, benefits from the host immune response, and utilizes virulence factors to directly and indirectly suppress members of the microbiota. However, $S$. Tm relies on members of the indigenous microbial community to expand its metabolic capabilities during infection that in turn promote outgrowth and transmission (Maier et al., 2013). Although some host factors and cytokines that are involved in the development of inflammation during infection are known (Behnsen et al., 2015), additional components are likely to contribute to $S$. Tm infection. A more comprehensive understanding of immune responses that contribute to dysbiosis and/or generate a nutritional niche for $S$. Tm is necessary to fully understand $S$. Tm infection strategies, and indeed, this remains an active area of research. Host inflammatory components could be enhancing intestinal pathology, restricting microbiota reconstitution, molding a new nutrient niche, or enhancing all aspects of infection.

\section{INTRAMACROPHAGE ADAPTATION}

After benefiting from components of the host immune response during intestinal colonization, $S$. Tm must withstand the bactericidal efforts of host phagocytes during systemic infection. $S$. Tm dissemination from the intestinal tract to systemic sites of infection largely depends on phagocytic cells (Vazquez-Torres et al., 1999). Of the host phagocytes, macrophages frequently interact with $S$. Tm during dissemination and within systemic sites, including the spleen and liver (Salcedo et al., 2001). Macrophages utilize several strategies such as acidification of phagosomes, generation of reactive oxygen and nitrogen species, and production of antimicrobial proteins and peptides to kill internalized pathogens (Flannagan et al., 2009); however, S. Tm is able to withstand these defense mechanisms through multiple molecular mechanisms. The T3SS-2 and associated secreted effectors create a replicative niche within macrophages termed the Salmonella containing vacuole (SCV) by modulating diverse host processes (Hensel et al., 1995; Ochman et al., 1996; Shea et al., 1996; Figueira and Holden, 2012). For example, these effectors inhibit SCV-lysosome fusion, modify host vesicle trafficking, localize the SCV within the cell, and evade the host autophagic response (Uchiya et al., 1999; Shotland et al., 2003; Guignot et al., 2004; Boucrot et al., 2005; Brumell and Scidmore, 2007; Jackson et al., 2008; Owen et al., 2014, 2016). Multiple environmental signals and bacterial regulators influence this critical adaptation step (discussed below).

\section{COUNTERACTING HOST DEFENSE MECHANISMS}

Pathogen recognition is the first line of defense for phagocytic cells such as macrophages. Host Toll-like receptors (TLRs) are transmembrane proteins located on the plasma membrane and endosomal membranes that recognize conserved molecular patterns associated with pathogens such as lipids, proteins, and nucleic acids (Kawai and Akira, 2010). TLRs have profound impacts on adaptive immunity and are thus broadly essential for host defense (Iwasaki and Medzhitov, 2004). Additionally, TLRs are critical for control of $S$. Tm replication as well as host survival during infection (Weiss et al., 2004). TLR activation and downstream signaling through the adapter proteins MyD88 and TRIF is linked to initial SCV acidification (Arpaia et al., 2011). The SCV acidifies rapidly following phagocytosis, dropping to a 
$\mathrm{pH}$ between 4.0 and 5.0 within 60 min of formation (Rathman et al., 1996). Acidification of the SCV is essential for S. Tm expression and functional formation of the T3SS-2 as well as secretion of effectors (Rathman et al., 1996; Beuzón et al., 1999; Hansen-Wester et al., 2002; Rappl et al., 2003; Arpaia et al., 2011; Chakraborty et al., 2015). Thus, S. Tm co-opts part of the macrophage defense system to serve as an initiating signal that promotes bacterial survival.

In the host, concentrations of free iron are extremely low in part to limit growth of invading pathogens (Kühn, 2015; Behnsen and Raffatellu, 2016). For example, the host expresses iron regulatory proteins (IRPs) and lipocalin-2 to limit the amount of iron available within macrophages (Kühn, 2015; Nairz et al., 2015a,b). Host-mediated iron limitation significantly restricts $S$. Tm replication within macrophages and reduces lethal disease (Nairz et al., 2015a). Additionally, IRP and lipocalin-2 influence the immune response during $S$. Tm infection (Nairz et al., 2015a,b). Indeed, modulating the immune response, specifically interleukin 10 , can rescue the bactericidal defects of lipocalin-2 deficient cells and mice (Nairz et al., 2015b). These results suggest that host iron concentrations indirectly affect $S$. Tm survival through alteration of the host immune response rather than by directly starving $S$. Tm of iron. Nonetheless, modulation of iron concentrations does influence $S$. Tm expression of virulence genes. For example, SPI-2 expression is reduced when $S$. Tm is grown in the presence of iron (Choi and Groisman, 2013; Choi et al., 2014), and the iron-sensing transcription factors Fur and PmrA limit SPI-2 expression during macrophage infection (Wösten et al., 2000; Choi and Groisman, 2013; Choi et al., 2014). However, SPI-2 expression has also been shown to be reduced when iron is chelated from cultures and during infection of macrophages that have low iron concentrations (Zaharik et al., 2002; Nairz et al., 2009). These contrasting findings require further investigation. Similarly, it is unclear what the iron availability is within the SCV with and without host iron acquisition mediators IRP and lipocalin-2.

Altogether, these findings highlight that $S$. Tm senses and responds to macrophage defense mechanisms, which impact $S$. Tm virulence and survival. By utilizing host defenses as signals, $S$. Tm incorporates antimicrobial processes into a bacterial signal transduction pathway that creates a suitable replication niche in an otherwise inhospitable environment.

\section{INTRAMACROPHAGE SENSING AND SIGNALING}

In addition to host defense-linked signals, $S$. Tm responds to concentrations of cations, nutrients, and ATP to activate expression of SPI-2 and other virulence factors to ensure survival (Valdivia and Falkow, 1997; Cirillo et al., 1998; Deiwick et al., 1999; Kim and Falkow, 2004; Löber et al., 2006; Osborne and Coombes, 2011; Lee and Groisman, 2012; Blair et al., 2013) (Figure 2). To sense these environmental signals and regulate SPI-2 expression, S. Tm uses several two-component systems (TCS) (Fass and Groisman, 2009). TCS are typically comprised of a sensor kinase that autophosphorylates upon sensing of a stimulus and then phosphorylates its paired response regulator, which in turn binds DNA to activate transcription of target genes (Stock et al., 2000). The PhoPQ TCS senses acidic pH, divalent cations, antimicrobial peptides, and potentially other signals to activate SPI-2 expression and modify components of the bacterial outer membrane (Bader et al., 2005; Prost et al., 2007; Dalebroux et al., 2014; Hicks et al., 2015). In addition to SPI-2, PhoP regulates other virulence factors, including the $m g t C B R$ operon. The $m g t C B R$ operon encodes an inner membrane protein, a $\mathrm{Mg}^{2+}$ transporter, and a regulator and is critical for intramacrophage survival (Soncini et al., 1996; BlancPotard and Groisman, 1997; Alix and Blanc-Potard, 2007; Lee and Groisman, 2010). It is still unclear what host or bacterial factors contribute to the presence of these SPI-2 activating signals within the SCV.

$S$. Tm also responds to signals that are not specific to the SCV, but rather are found in multiple environments throughout the host. For example, the host hormones epinephrine and norepinephrine (epi/NE) are ubiquitous throughout the body (Boyanova, 2017). The bacterial TCS QseBC and QseEF sense and respond to epi/NE during infection (Clarke et al., 2006; Reading et al., 2009). The sensor kinase QseC regulates the expression of genes encoded within SPI-1 and enhances epithelial cell invasion under conditions that promote SPI-1 expression (Moreira et al., 2010). Additionally, during macrophage infection, QseC activates SPI-2 expression to enhance intramacrophage survival (Moreira et al., 2010). Moreover, both epi/NE-responsive histidine sensor kinases, QseC and QseE, are required for systemic infection (Rasko et al., 2008; Moreira et al., 2010; Moreira and Sperandio, 2012). NE induces expression of both SPI-1 and SPI-2 associated genes, however, only expression of SPI-2 associated genes is QseC dependent (Moreira et al., 2010). These findings reveal that the same signal (epi or NE) enhances $S$. Tm virulence gene expression depending on the surrounding environment. The additional components of the intramacrophage environment that allow these epi/NE-dependent signaling pathways to distinguish between a SPI-1 or SPI-2 inducing condition warrant further studies.

Ethanolamine is another signal that plays environmentdependent roles in expression of $S$. Tm virulence traits (Anderson and Kendall, 2016). Ethanolamine is present in serum and is maintained intracellularly by host cells in part to recycle and produce phosphatidylethanolamine (Nikawa et al., 1986; Lipton et al., 1988, 1990; Sandra and Cai, 1991; Shiao and Vance, 1995). In the Enterobacteriaceae, including $S$. Tm, the transcription factor EutR directly senses ethanolamine (Roof and Roth, 1992; Luzader et al., 2013). EutR-dependent signaling promotes ethanolamine metabolism during intestinal infection (Anderson et al., 2015). As infection progresses, ethanolamine promotes $S$. Tm dissemination to systemic sites independently of metabolism (Anderson et al., 2015). Although ethanolamine metabolism does not provide a growth benefit for $S$. Tm during systemic infection (Stojiljkovic et al., 1995; Thiennimitr et al., 2011; Steeb et al., 2013; Anderson et al., 2015), EutR directly activates expression of SPI-2 within macrophages leading to increased survival and early dissemination (Anderson et al., 2015). It is 


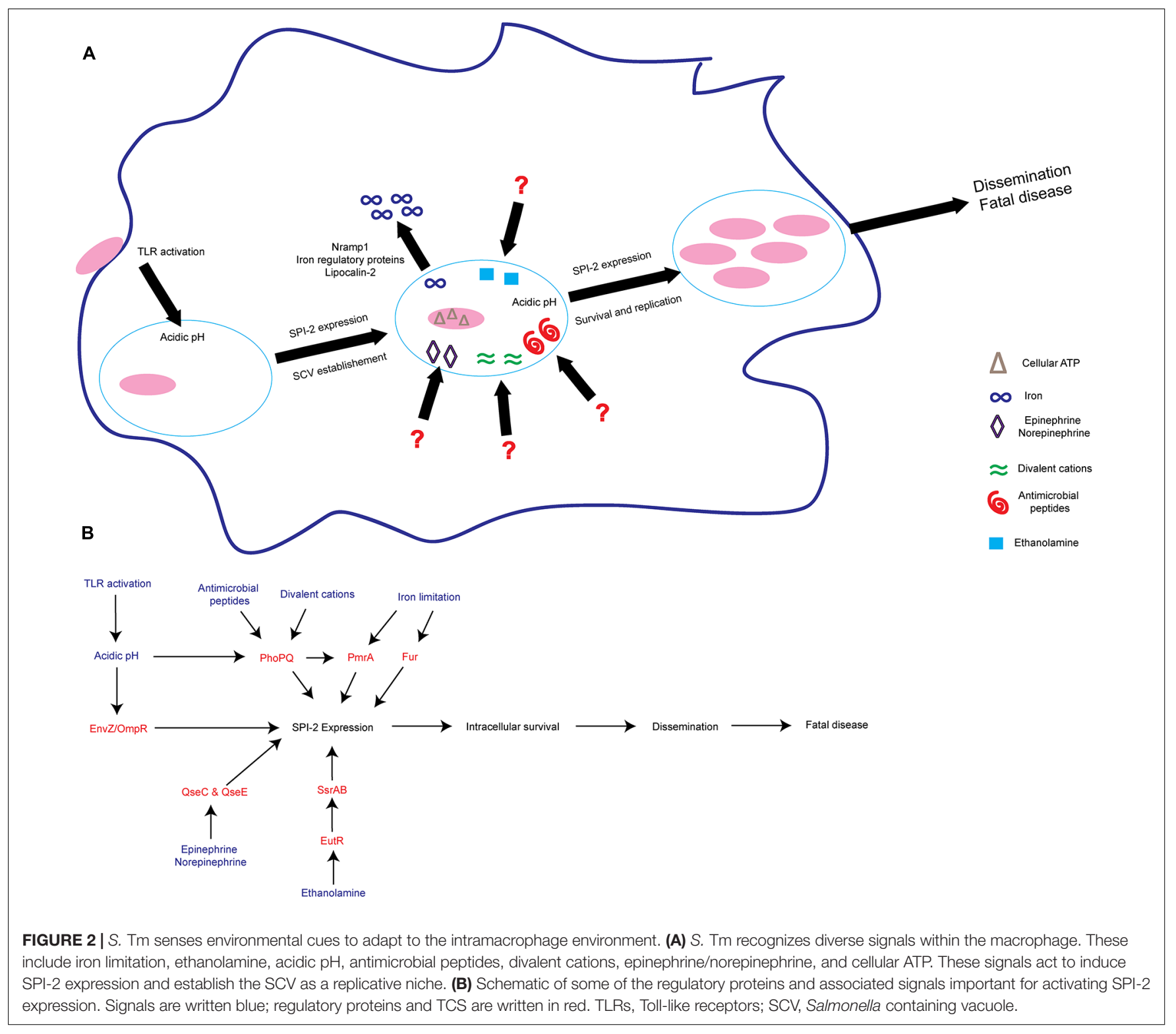

currently unclear how ethanolamine can signal through the same receptor, EutR, to promote niche adaptation in distinct host environments. However, it is clear that ethanolamine plays a dual role in $S$. Tm infection by supporting growth in the inflamed intestine as well as enhancing subsequent stages of $S$. Tm disease.

The production of Salmonella-induced filaments (SIFs) is a critical component of $S$. Tm adaptation to intracellular environments (Garcia-del Portillo et al., 1993; Stein et al., 1996). This SIF network remodels the host endosomal network, allowing $S$. Tm to gain access to endocytosed molecules (Ohlson et al., 2008; Liss et al., 2017). The SCV/SIF continuum is required for efficient intracellular metabolism and promotes S. Tm replication (Liss et al., 2017). While the focus of this study was on access to metabolites (Liss et al., 2017), the same principle of incorporating extracellular molecules into the SCV may be true for signaling molecules that promote virulence. In such a model, signaling molecules present within host endosomes, or recently endocytosed molecules from the extracellular environment, would be shuttled through the SCV/SIF continuum and potentially impact $S$. Tm virulence gene expression. This revelation opens the possibility that large sets of molecules within various host tissues are able to reach the SCV within macrophages in vivo. Additionally, genes that have previously been identified as not being induced during macrophage infection in vitro may be the result of a relevant signal being absent from the culture conditions. Determining in vivo signals that $S$. Tm recognizes remains a daunting challenge but is necessary for a thorough understanding of the events that trigger intracellular adaptation.

The majority of work on environmental signals and sensing within macrophages has focused on transcriptional regulation; however, recent proteomic and RNA-seq approaches have shown 
that regulation of gene expression is more complex. Posttranslational modifications as well as small regulatory RNA (sRNA)-induced post-transcriptional changes regulate virulence during macrophage infection (Ansong et al., 2013; Westermann et al., 2016). sRNAs are non-coding 50-500 nucleotide transcripts that utilize base-pair interactions to post-transcriptionally regulate the expression of target mRNAs (Hébrard et al., 2012). S. Tm encodes approximately 300 unique sRNAs, and the expression of a subset of sRNAs is highly sensitive to signals encountered within the macrophage environment, such as nutrient starvation, and are controlled by key components of the SPI-2 regulatory system (Kröger et al., 2012, 2013; Amin et al., 2016; Colgan et al., 2016). Specifically, the sRNA PinT regulates SPI-2 expression and is critical for host adaptation in vivo (Chaudhuri et al., 2013; Westermann et al., 2016). It is possible that post-transcriptional regulation helps $S$. Tm incorporate environmental signals sensed within the SCV to modulate survival.

In addition to active intracellular replication, entering a non-replicating yet viable state is an alternative adaptation strategy. A portion of the infecting $S$. Tm population enters a persistent state within macrophages that is independent of SPI-2 (Helaine et al., 2010). These non-replicating S. Tm remain viable and are not killed by macrophage antimicrobial defenses (Helaine et al., 2010). This phenomenon has also been demonstrated within non-phagocytic cells in vivo (NúñezHernández et al., 2013). It is unclear how these persister cells impact disease progression in vivo, but perhaps persister cells promote asymptomatic carriage and transmission. Future studies are required to determine if there is transcriptional overlap between these persister cells and actively replicating $S$. Tm or if perhaps post-transcriptional regulation contributes to this phenotypic switch. Advancements in single cell expression techniques will allow replicating and dormant cells to be distinguished from one another. Similarly, it remains unclear what signals present within the SCV trigger the shift from replication to persistence. Although distinct signals may be responsible for transitioning to a persistent state, it is also possible that loss of the signals important for replication leads to dormancy.

Altogether, these studies reveal complex and dynamic regulatory circuits important for $S$. Tm survival within macrophages. S. Tm must appropriately repress and activate virulence gene expression to ensure adaptation to the SCV (Kato et al., 2003; Choi and Groisman, 2013; Westermann et al., 2016). Additionally, $S$. Tm must be able to initiate distinct regulatory pathways at different time points during infection (Moreira et al., 2010; Moreira and Sperandio, 2012; Anderson et al., 2015). Further understanding of these activating and suppressing cues, and how they are balanced with one another, will enhance our understanding of $S$. Tm pathogenesis.

\section{HOST CELL DEATH}

The replication-suitable SCV within macrophages is a temporary niche, as host cells die. The way in which cells die has a tremendous impact on host physiology and inflammation (Pasparakis and Vandenabeele, 2015; Medina and Ravichandran, 2016). Programmed host cell death can be classified based on the effector proteins required and the state of inflammation each type of death induces (Kroemer et al., 2009). Three of the major programmed cell death pathways are apoptosis, necroptosis, and pyroptosis (Kroemer et al., 2009). S. Tm infection induces apoptosis-like features in infected macrophages including chromatin condensation and caspase-3 and caspase8 activity (Chen et al., 1996; Lindgren et al., 1996; Monack et al., 1996; van der Velden et al., 2000; Man et al., 2013; Günster et al., 2017). Additionally, S. Tm infection can induce RIPK3 and MLKL-dependent necroptosis (Robinson et al., 2012; Günster et al., 2017). The best-characterized form of $S$. Tm-induced cell death is caspase-1/caspase-11-dependent pyroptosis (Brennan and Cookson, 2000; Monack et al., 2001; Fink and Cookson, 2006; Fink et al., 2008). Host cells employ several means to recognize $S$. Tm virulence proteins and initiate regulated pyroptosis. For example, macrophage NLRC4 (Ipaf) recognizes $S$. Tm flagellin and components of T3SS-1 to activate caspase-1 (Franchi et al., 2006; Miao et al., 2006, 2010b; Zhao et al., 2011). Additionally, macrophage NAIP1 also recognizes components of T3SS-1 to initiate a pyroptotic death (Rayamajhi et al., 2013; Yang et al., 2013). Caspase-1 and caspase-11, as well as their activators NLRP3 and NLRC4, impact $S$. Tm pathogenesis and bacterial burden in vivo (LaraTejero et al., 2006; Raupach et al., 2006; Broz et al., 2010, 2012). Interestingly, the host is able to enhance clearance of $S$. Tm infection when pyroptosis is experimentally induced in vivo (Miao et al., 2010a; Stewart et al., 2011; Aachoui et al., 2013; Jorgensen et al., 2016). These findings suggest that $S$. Tm might try to evade inducing host cell death during some stages of infection. Although most commonly studied in macrophages, $S$. Tm-induced cell death also occurs in dendritic and epithelial cells (van der Velden et al., 2003; Sellin et al., 2014; Rauch et al., 2017). It remains uncertain if infected cells are simply overwhelmed by $S$. Tm over time in vitro, if $S$. Tm actively regulates virulence to promote or evade host cell death in vivo, if cell death is occurring throughout infection, and what the consequences of host cell death are during systemic disease.

\section{CONCLUSION}

$S$. Tm is able to recognize, adapt to, and survive within the intestinal tract and the intramacrophage environment during infection. These two environments present very different obstacles to infection, and $S$. Tm utilizes diverse strategies to overcome these distinct barriers. A better understanding of the signaling molecules, the signal transduction pathways, and the cross talk between signal transduction pathways that promote niche recognition may provide novel opportunities for therapeutic intervention. Importantly, several of the strategies used by $S$. Tm to adapt to host environments are conserved among several organisms such as pathogenic E. coli, Listeria monocytogenes, Brucella abortus, and Staphylococcus aureus. For 
example, pathogens adapt to the host or regulate virulence by utilizing and/or sensing nitrate (Spees et al., 2013; Winter et al., 2013), epi/NE (Curtis et al., 2014; Halang et al., 2015; Moreira et al., 2016; Rooks et al., 2017), ethanolamine (Maadani et al., 2007; Kendall et al., 2012; DebRoy et al., 2014; Gonyar and Kendall, 2014; Mellin et al., 2014; Subashchandrabose et al., 2014), iron (Almirón et al., 2001; Zimbler et al., 2012; Hammer et al., 2013, 2014; Mashruwala et al., 2015; Palmer and Skaar, 2016), and pH (Heinzen et al., 1996; SturgillKoszycki and Swanson, 2000; Singh et al., 2008; Vandal et al., 2008). Additionally, T6SS are widely conserved, particularly within Proteobacteria and Bacteroidetes (Hood et al., 2017), and promote colonization of intestinal pathogens ( $\mathrm{Fu}$ et al., 2013; Sana et al., 2017). Perhaps the fact that S. Tm utilizes all of these strategies, rather than a select few, makes $S$. Tm so successful and such a major burden on global healthcare (Scallan et al., 2011). Therefore, further study of these environmental

\section{REFERENCES}

Aachoui, Y., Leaf, I. A., Hagar, J. A., Fontana, M. F., Campos, C. G., Zak, D. E., et al. (2013). Caspase-11 protects against bacteria that escape the vacuole. Science 339, 975-978. doi: 10.1126/science.1230751

Acheson, D., and Hohmann, E. L. (2001). Nontyphoidal salmonellosis. Clin. Infect. Dis. 32, 263-269. doi: 10.1086/318457

Ali, M. M., Newsom, D. L., Gonzalez, J. F., Sabag-Daigle, A., Stahl, C., Steidley, B., et al. (2014). Fructose-asparagine is a primary nutrient during growth of Salmonella in the inflamed intestine. PLOS Pathog. 10:e1004209. doi: 10.1371/ journal.ppat.1004209

Alix, E., and Blanc-Potard, A.-B. (2007). MgtC: a key player in intramacrophage survival. Trends Microbiol. 15, 252-256. doi: 10.1016/j.tim.2007.03.007

Almirón, M., Martínez, M., Sanjuan, N., and Ugalde, R. A. (2001). Ferrochelatase is present in Brucella abortus and is critical for its intracellular survival and virulence. Infect. Immun. 69, 6225-6230. doi: 10.1128/IAI.69.10.6225-6230. 2001

Amin, S. V., Roberts, J. T., Patterson, D. G., Coley, A. B., Allred, J. A., Denner, J. M., et al. (2016). Novel small RNA (sRNA) landscape of the starvation-stress response transcriptome of Salmonella enterica serovar typhimurium. RNA Biol. 13, 331-342. doi: 10.1080/15476286.2016.1144010

Anderson, C. J., and Kendall, M. M. (2016). Location, location, location. Salmonella senses ethanolamine to gauge distinct host environments and coordinate gene expression. Microb. Cell 3, 89-91. doi: 10.15698/mic2016.02.479

Anderson, C. J., Clark, D. E., Adli, M., and Kendall, M. M. (2015). Ethanolamine signaling promotes Salmonella niche recognition and adaptation during infection. PLOS Pathog. 11:e1005278. doi: 10.1371/journal.ppat. 1005278

Ansari, S., Sherchand, J. B., Parajuli, K., Mishra, S. K., Dahal, R. K., Shrestha, S., et al. (2012). Bacterial etiology of acute diarrhea in children under five years of age. J. Nepal Health Res. Counc. 10, 218-223.

Ansong, C., Wu, S., Meng, D., Liu, X., Brewer, H. M., Kaiser, B. L. D., et al. (2013). Top-down proteomics reveals a unique protein S-thiolation switch in Salmonella Typhimurium in response to infection-like conditions. Proc. Natl. Acad. Sci. U.S.A. 110, 10153-10158. doi: 10.1073/pnas.1221210110

Arpaia, N., Godec, J., Lau, L., Sivick, K. E., McLaughlin, L. M., Jones, M. B., et al. (2011). TLR signaling is required for Salmonella typhimurium virulence. Cell 144, 675-688. doi: 10.1016/j.cell.2011.01.031

Bader, M. W., Sanowar, S., Daley, M. E., Schneider, A. R., Cho, U., Xu, W., et al. (2005). Recognition of antimicrobial peptides by a bacterial sensor kinase. Cell 122, 461-472. doi: 10.1016/j.cell.2005.05.030

Bajaj, V., Hwang, C., and Lee, C. A. (1995). hilA is a novel ompR/toxR family member that activates the expression of Salmonella typhimurium invasion genes. Mol. Microbiol. 18, 715-727. doi: 10.1111/j.1365-2958.1995. mmi_18040715.x adaptation strategies, using $S$. Tm as a model organism, will enhance our understanding of the host-microbiota-pathogen interface.

\section{AUTHOR CONTRIBUTIONS}

All authors listed have made a substantial, direct and intellectual contribution to the work, and approved it for publication.

\section{FUNDING}

Work in the MMK lab is supported by the National Institutes of Health (NIH) grant AI118732. CA was supported through NIH training grant 5T32AI007046 and University of Virginia School of Medicine Wagner Fellowship.

Bajaj, V., Lucas, R. L., Hwang, C., and Lee, C. A. (1996). Co-ordinate regulation of Salmonella typhimurium invasion genes by environmental and regulatory factors is mediated by control of HilA expression. Mol. Microbiol. 22, 703-714. doi: 10.1046/j.1365-2958.1996.d01-1718.x

Bakovic, M., Fullerton, M. D., and Michel, V. (2007). Metabolic and molecular aspects of ethanolamine phospholipid biosynthesis: the role of ctp:phosphoethanolamine cytidylyltransferase (pcyt2). Biochem. Cell Biol. 85, 283-300. doi: 10.1139/O07-006

Barman, M., Unold, D., Shifley, K., Amir, E., Hung, K., Bos, N., et al. (2008). Enteric salmonellosis disrupts the microbial ecology of the murine gastrointestinal tract. Infect. Immun. 76, 907-915. doi: 10.1128/IAI.01432-07

Barthel, M., Hapfelmeier, S., Quintanilla-Martinez, L., Kremer, M., Rohde, M., Hogardt, M., et al. (2003). Pretreatment of mice with streptomycin provides a Salmonella enterica serovar typhimurium colitis model that allows analysis of both pathogen and host. Infect. Immun. 71, 2839-2858. doi: 10.1128/IAI.71.5. 2839-2858.2003

Basler, M., Pilhofer, M., Henderson, P. G., Jensen, J. G., and Mekalanos, J. (2012). Type VI secretion requires a dynamic contractile phage tail-like structure. Nature 483, 182-186. doi: 10.1038/nature10846

Bäumler, A. J., and Sperandio, V. (2016). Interactions between the microbiota and pathogenic bacteria in the gut. Nature 535, 85-93. doi: 10.1038/nature18849

Behnsen, J., Jellbauer, S., Wong, C. P., Edwards, R. A., George, M. D., Ouyang, W., et al. (2014). The cytokine Il-22 promotes pathogen colonization by suppressing related commensal bacteria. Immunity 40, 262-273. doi: 10.1016/j.immuni. 2014.01.003

Behnsen, J., Perez-Lopez, A., Nuccio, S.-P., and Raffatellu, M. (2015). Exploiting host immunity: the Salmonella paradigm. Trends Immunol. 36, 112-120. doi: $10.1016 /$ j.it.2014.12.003

Behnsen, J., and Raffatellu, M. (2016). Siderophores: more than stealing iron. mBio 7:e01906-16. doi: 10.1128/mBio.01906-16

Beuzón, C. R., Banks, G., Deiwick, J., Hensel, M., and Holden, D. W. (1999). pHdependent secretion of SseB, a product of the Spi-2 type III secretion system of Salmonella typhimurium. Mol. Microbiol. 33, 806-816. doi: 10.1046/j.13652958.1999.01527.x

Bingle, L. E., Bailey, C. M., and Pallen, M. J. (2008). Type VI secretion: a beginner's guide. Curr. Opin. Microbiol. 11, 3-8. doi: 10.1016/j.mib.2008.01.006

Blair, J. M. A., Richmond, G. E., Bailey, A. M., Ivens, A., and Piddock, L. J. V. (2013). Choice of bacterial growth medium alters the transcriptome and phenotype of Salmonella enterica serovar typhimurium. PLOS ONE 8:e63912. doi: 10.1371/ journal.pone.0063912

Blanc-Potard, A. B., and Groisman, E. A. (1997). The Salmonella selC locus contains a pathogenicity island mediating intramacrophage survival. EMBO J. 16, 5376-5385. doi: 10.1093/emboj/16.17.5376

Bogomolnaya, L. M., Andrews, K. D., Talamantes, M., Maple, A., Ragoza, Y., Vazquez-Torres, A., et al. (2013). The ABC-type efflux pump MacAB protects 
Salmonella enterica serovar typhimurium from oxidative stress. mBio 4:e0063013. doi: $10.1128 / \mathrm{mBio} .00630-13$

Bönemann, G., Pietrosiuk, A., Diemand, A., Zentgraf, H., and Mogk, A. (2009). Remodelling of VipA/VipB tubules by Clpv-mediated threading is crucial for type VI protein secretion. EMBO J. 28, 315-325. doi: 10.1038/emboj.2008.269

Boucrot, E., Henry, T., Borg, J.-P., Gorvel, J.-P., and Méresse, S. (2005). The intracellular fate of Salmonella depends on the recruitment of kinesin. Science 308, 1174-1178. doi: 10.1126/science.1110225

Boyanova, L. (2017). Stress hormone epinephrine (adrenaline) and Norepinephrine (noradrenaline) effects on the anaerobic bacteria. Anaerobe 44, 13-19. doi: 10.1016/j.anaerobe.2017.01.003

Brennan, M. A., and Cookson, B. T. (2000). Salmonella induces macrophage death by caspase-1-dependent necrosis. Mol. Microbiol. 38, 31-40. doi: 10.1046/j. 1365-2958.2000.02103.x

Brochier-Armanet, C., Talla, E., and Gribaldo, S. (2009). The multiple evolutionary histories of dioxygen reductases: implications for the origin and evolution of aerobic respiration. Mol. Biol. Evol. 26, 285-297. doi: 10.1093/molbev/msn246

Broz, P., Newton, K., Lamkanfi, M., Mariathasan, S., Dixit, V. M., and Monack, D. M. (2010). Redundant roles for inflammasome receptors NLRP3 and NLRC4 in Host defense against Salmonella. J. Exp. Med. 207, 1745-1755. doi: 10.1084/ jem.20100257

Broz, P., Ruby, T., Belhocine, K., Bouley, D. M., Kayagaki, N., Dixit, V. M., et al. (2012). Caspase-11 increases susceptibility to Salmonella infection in the absence of caspase-1. Nature 490, 288-291. doi: 10.1038/nature11419

Brugiroux, S., Beutler, M., Pfann, C., Garzetti, D., Ruscheweyh, H.-J., Ring, D., et al. (2016). Genome-guided design of a defined mouse microbiota that confers colonization resistance against Salmonella enterica serovar typhimurium. Nat. Microbiol. 2:16215. doi: 10.1038/nmicrobiol.2016.215

Brumell, J. H., and Scidmore, M. A. (2007). Manipulation of Rab GTPase function by intracellular bacterial pathogens. Microbiol. Mol. Biol. Rev. 71, 636-652. doi: 10.1128/MMBR.00023-07

Brunet, Y. R., Khodr, A., Logger, L., Aussel, L., Mignot, T., Rimsky, S., et al. (2015). H-NS silencing of the Salmonella pathogenicity island 6-encoded type VI secretion system limits Salmonella enterica serovar typhimurium interbacterial killing. Infect. Immun. 83, 2738-2750. doi: 10.1128/IAI.00198-15

Carreau, A., Hafny-Rahbi, B. E., Matejuk, A., Grillon, C., and Kieda, C. (2011). Why is the partial oxygen pressure of human tissues a crucial parameter? Small molecules and hypoxia. J. Cell. Mol. Med. 15, 1239-1253. doi: 10.1111/j.15824934.2011.01258.x

Cash, H. L., Whitham, C. V., Behrendt, C. L., and Hooper, L. V. (2006). Symbiotic bacteria direct expression of an intestinal bactericidal lectin. Science 313, 1126-1130. doi: 10.1126/science.1127119

Chakraborty, S., Mizusaki, H., and Kenney, L. J. (2015). A FRET-based DNA biosensor tracks OmpR-dependent acidification of Salmonella during macrophage infection. PLOS Biol. 13:e1002116. doi: 10.1371/journal.pbio. 1002116

Chaudhuri, R. R., Morgan, E., Peters, S. E., Pleasance, S. J., Hudson, D. L., Davies, H. M., et al. (2013). Comprehensive assignment of roles for Salmonella typhimurium genes in intestinal colonization of food-producing animals. PLOS Genet. 9:e1003456. doi: 10.1371/journal.pgen.1003456

Chen, L. M., Kaniga, K., and Galán, J. E. (1996). Salmonella spp. are cytotoxic for cultured macrophages. Mol. Microbiol. 21, 1101-1115. doi: 10.1046/j.13652958.1996.471410.x

Choi, E., Kim, H., Lee, H., Nam, D., Choi, J., and Shin, D. (2014). The iron-sensing fur regulator controls expression timing and levels of Salmonella pathogenicity island 2 genes in the course of environmental acidification. Infect. Immun. 82, 2203-2210. doi: 10.1128/IAI.01625-13

Choi, J., and Groisman, E. A. (2013). The lipopolysaccharide modification regulator PmrA limits Salmonella virulence by repressing the type threesecretion system Spi/Ssa. Proc. Natl. Acad. Sci. U.S.A. 110, 9499-9504. doi: 10.1073/pnas. 1303420110

Cianfanelli, F. R., Monlezun, L., and Coulthurst, S. J. (2016). Aim, load, fire: the type VI secretion system, a bacterial nanoweapon. Trends Microbiol. 24, 51-62. doi: 10.1016/j.tim.2015.10.005

Cirillo, D. M., Valdivia, R. H., Monack, D. M., and Falkow, S. (1998). Macrophagedependent induction of the Salmonella pathogenicity island 2 type III secretion system and its role in intracellular survival. Mol. Microbiol. 30, 175-188. doi: 10.1046/j.1365-2958.1998.01048.x
Clarke, M. B., Hughes, D. T., Zhu, C., Boedeker, E. C., and Sperandio, V. (2006). The QseC sensor kinase: a bacterial adrenergic receptor. Proc. Natl. Acad. Sci. U.S.A. 103, 10420-10425. doi: 10.1073/pnas.0604343103

Coburn, B., Li, Y., Owen, D., Vallance, B. A., and Finlay, B. B. (2005). Salmonella enterica serovar typhimurium pathogenicity island 2 is necessary for complete virulence in a mouse model of infectious enterocolitis. Infect. Immun. 73, 3219-3227. doi: 10.1128/IAI.73.6.3219-3227.2005

Colgan, A. M., Kröger, C., Diard, M., Hardt, W.-D., Puente, J. L., Sivasankaran, S. K., et al. (2016). The impact of 18 ancestral and horizontally-acquired regulatory proteins upon the transcriptome and sRNA landscape of Salmonella enterica serovar typhimurium. PLOS Genet. 12:e1006258. doi: 10.1371/journal. pgen. 1006258

Cotton, P. B. (1972). Non-dietary lipid in the intestinal lumen. Gut 13, 675-681. doi: 10.1136/gut.13.9.675

Crouch, M.-L. V., Castor, M., Karlinsey, J. E., Kalhorn, T., and Fang, F. C. (2008). Biosynthesis and IroC-dependent export of the siderophore salmochelin are essential for virulence of Salmonella enterica serovar typhimurium. Mol. Microbiol. 67, 971-983. doi: 10.1111/j.1365-2958.2007.06089.x

Curtis, M. M., Russell, R., Moreira, C. G., Adebesin, A. M., Wang, C., Williams, N. S., et al. (2014). QseC inhibitors as an antivirulence approach for gramnegative pathogens. mBio 5:e2165-14. doi: 10.1128/mBio.02165-14

Dalebroux, Z. D., Matamouros, S., Whittington, D., Bishop, R. E., and Miller, S. I. (2014). PhoPQ regulates acidic glycerophospholipid content of the Salmonella Typhimurium outer membrane. Proc. Natl. Acad. Sci. U.S.A. 111, 1963-1968. doi: 10.1073/pnas.1316901111

Dawaliby, R., Trubbia, C., Delporte, C., Noyon, C., Ruysschaert, J.-M., Antwerpen, P. V., et al. (2015). Phosphatidylethanolamine is a key regulator of membrane fluidity in eukaryotic cells. J. Biol. Chem. 291, 3658-3667. doi: 10.1074/jbc. M115.706523

DebRoy, S., Gebbie, M., Ramesh, A., Goodson, J. R., Cruz, M. R., van Hoof, A., et al. (2014). Riboswitches. a riboswitch-containing sRNA controls gene expression by sequestration of a response regulator. Science 345, 937-940. doi: 10.1126/ science. 1255091

Deiwick, J., Nikolaus, T., Erdogan, S., and Hensel, M. (1999). Environmental regulation of Salmonella pathogenicity island 2 gene expression. Mol. Microbiol. 31, 1759-1773. doi: 10.1046/j.1365-2958.1999.01312.x

Deng, W., Marshall, N. C., Rowland, J. L., McCoy, J. M., Worrall, L. J., Santos, A. S., et al. (2017). Assembly, structure, function and regulation of type III secretion systems. Nat. Rev. Microbiol. 15, 323-337. doi: 10.1038/nrmicro. 2017.20

Deriu, E., Liu, J. Z., Pezeshki, M., Edwards, R. A., Ochoa, R. J., Contreras, H., et al. (2013). Probiotic bacteria reduce Salmonella typhimurium intestinal colonization by competing for iron. Cell Host Microbe 14, 26-37. doi: 10.1016/ j.chom.2013.06.007

Dewhirst, F. E., Chien, C.-C., Paster, B. J., Ericson, R. L., Orcutt, R. P., Schauer, D. B., et al. (1999). Phylogeny of the defined murine microbiota: altered schaedler flora. Appl. Environ. Microbiol. 65, 3287-3292.

Diard, M., Sellin, M. E., Dolowschiak, T., Arnoldini, M., Ackermann, M., and Hardt, W.-D. (2014). Antibiotic treatment selects for cooperative virulence of Salmonella Typhimurium. Curr. Biol. 24, 2000-2005. doi: 10.1016/j.cub.2014. 07.028

Diaz-Ochoa, V. E., Lam, D., Lee, C. S., Klaus, S., Behnsen, J., Liu, J. Z., et al. (2016). Salmonella mitigates oxidative stress and thrives in the inflamed gut by evading calprotectin-mediated manganese sequestration. Cell Host Microbe 19, 814-825. doi: 10.1016/j.chom.2016.05.005

Donohoe, D. R., Wali, A., Brylawski, B. P., and Bultman, S. J. (2012). Microbial regulation of glucose metabolism and cell-cycle progression in mammalian colonocytes. PLOS ONE 7:e46589. doi: 10.1371/journal.pone.0046589

Dowhan, W. (1997). Phosphatidylserine decarboxylases: pyruvoyl-dependent enzymes from bacteria to mammals. Methods Enzymol. 280, 81-88. doi: $10.1016 /$ S0076-6879(97)80104-8

Dowhan, W. (2003). Molecular basis for membrane phospholipid diversity: why are there so many lipids? Annu. Rev. Biochem. 66, 199-232. doi: 10.1146/ annurev.biochem.66.1.199

Drumo, R., Pesciaroli, M., Ruggeri, J., Tarantino, M., Chirullo, B., Pistoia, C., et al. (2016). Salmonella enterica serovar typhimurium exploits inflammation to modify swine intestinal microbiota. Front. Cell. Infect. Microbiol. 5:106. doi: 10.3389/fcimb.2015.00106 
Eade, C. R., Hung, C.-C., Bullard, B., Gonzalez-Escobedo, G., Gunn, J. S., and Altier, C. (2016). Bile acids function synergistically to repress invasion gene expression in Salmonella by destabilizing the invasion regulator HilD. Infect. Immun. 84, 2198-2208. doi: 10.1128/IAI.00177-16

Edwards, J. C., Johnson, M. S., and Taylor, B. L. (2006). Differentiation between electron transport sensing and proton motive force sensing by the Aer and Tsr receptors for aerotaxis. Mol. Microbiol. 62, 823-837. doi: 10.1111/j.1365-2958. 2006.05411.x

Ellermeier, C. D., Ellermeier, J. R., and Slauch, J. M. (2005). HilD, HilC and RtsA constitute a feed forward loop that controls expression of the SPI1 type three secretion system regulator HilA in Salmonella enterica serovar typhimurium. Mol. Microbiol. 57, 691-705. doi: 10.1111/j.1365-2958.2005.04737.x

Ellermeier, C. D., and Slauch, J. M. (2004). RtsA coordinately regulates DsbA and the Salmonella pathogenicity island 1 type III secretion system. J. Bacteriol. 186, 68-79. doi: 10.1128/JB.186.1.68-79.2004

Endt, K., Stecher, B., Chaffron, S., Slack, E., Tchitchek, N., Benecke, A., et al. (2010). The microbiota mediates pathogen clearance from the gut lumen after nontyphoidal Salmonella diarrhea. PLOS Pathog. 6:e1001097. doi: 10.1371/journal. ppat. 1001097

Espey, M. G. (2013). Role of oxygen gradients in shaping redox relationships between the human intestine and its microbiota. Free Radic. Biol. Med. 55, 130-140. doi: 10.1016/j.freeradbiomed.2012.10.554

Faber, F., Thiennimitr, P., Spiga, L., Byndloss, M. X., Litvak, Y., Lawhon, S., et al. (2017). Respiration of microbiota-derived 1,2-propanediol drives Salmonella expansion during colitis. PLOS Pathog. 13:e1006129. doi: 10.1371/journal.ppat. 1006129

Fàbrega, A., and Vila, J. (2013). Salmonella enterica serovar typhimurium skills to succeed in the host: virulence and regulation. Clin. Microbiol. Rev. 26, 308-341. doi: 10.1128/CMR.00066-12

Fass, E., and Groisman, E. A. (2009). Control of Salmonella pathogenicity island-2 gene expression. Curr. Opin. Microbiol. 12, 199-204. doi: 10.1016/j.mib.2009. 01.004

Figueira, R., and Holden, D. W. (2012). Functions of the Salmonella pathogenicity island 2 (SPI-2) type III secretion system effectors. Microbiology 158, 1147-1161. doi: 10.1099/mic.0.058115-0

Fink, S. L., Bergsbaken, T., and Cookson, B. T. (2008). Anthrax lethal toxin and Salmonella elicit the common cell death pathway of caspase-1-dependent pyroptosis via distinct mechanisms. Proc. Natl. Acad. Sci. U.S.A. 105, 4312-4317. doi: 10.1073/pnas.0707370105

Fink, S. L., and Cookson, B. T. (2006). Caspase-1-dependent pore formation during pyroptosis leads to osmotic lysis of infected host macrophages. Cell. Microbiol. 8, 1812-1825. doi: 10.1111/j.1462-5822.2006.00751.x

Flannagan, R. S., Cosío, G., and Grinstein, S. (2009). Antimicrobial mechanisms of phagocytes and bacterial evasion strategies. Nat. Rev. Microbiol. 7, 355-366. doi: $10.1038 /$ nrmicro2128

Franchi, L., Amer, A., Body-Malapel, M., Kanneganti, T.-D., Özören, N., Jagirdar, R., et al. (2006). Cytosolic flagellin requires Ipaf for activation of caspase-1 and interleukin $1 \beta$ in Salmonella-infected macrophages. Nat. Immunol. 7, 576-582. doi: 10.1038/ni1346

Fu, Y., Waldor, M. K., and Mekalanos, J. J. (2013). Tn-Seq analysis of Vibrio cholerae intestinal colonization reveals a role for T6SS-mediated antibacterial activity in the host. Cell Host Microbe 14, 652-663. doi: 10.1016/j.chom.2013.11.001

Galán, J. E., and Curtiss, R. (1989). Cloning and molecular characterization of genes whose products allow Salmonella typhimurium to penetrate tissue culture cells. Proc. Natl. Acad. Sci. U.S.A. 86, 6383-6387. doi: 10.1073/pnas.86.16.6383

Galán, J. E., and Curtiss, R. (1990). Expression of Salmonella typhimurium genes required for invasion is regulated by changes in DNA supercoiling. Infect. Immun. 58, 1879-1885.

Galanis, E., Lo Fo Wong, D. M., Patrick, M. E., Binsztein, N., Cieslik, A., Chalermchaikit, T., et al. (2006). Web-based surveillance and global Salmonella distribution, 2000-2002. Emerg. Infect. Dis. 12, 381-388. doi: 10.3201/eid1203. 050854

Gantois, I., Ducatelle, R., Pasmans, F., Haesebrouck, F., Hautefort, I., Thompson, A., et al. (2006). Butyrate specifically down-regulates Salmonella pathogenicity island 1 gene expression. Appl. Environ. Microbiol. 72, 946-949. doi: 10.1128/AEM.72.1.946-949.2006

Garcia-del Portillo, F., Zwick, M. B., Leung, K. Y., and Finlay, B. B. (1993). Salmonella induces the formation of filamentous structures containing lysosomal membrane glycoproteins in epithelial cells. Proc. Natl. Acad. Sci. U.S.A. 90, 10544-10548. doi: 10.1073/pnas.90.22.10544

Gart, E. V., Suchodolski, J. S., Welsh, T. H., Alaniz, R. C., Randel, R. D., and Lawhon, S. D. (2016). Salmonella typhimurium and multidirectional communication in the gut. Front. Microbiol. 7:1827. doi: 10.3389/fmicb.2016. 01827

Gibson, G. R., and Roberfroid, M. B. (1995). Dietary modulation of the human colonic microbiota: introducing the concept of prebiotics. J. Nutr. 125, 1401-1412.

Gill, N., Ferreira, R. B. R., Antunes, L. C. M., Willing, B. P., Sekirov, I., Al-Zahrani, F., et al. (2012). Neutrophil elastase alters the murine gut microbiota resulting in enhanced Salmonella colonization. PLOS ONE 7:e49646. doi: 10.1371/journal.pone.0049646

Godinez, I., Haneda, T., Raffatellu, M., George, M. D., Paixão, T. A., Rolán, H. G., et al. (2008). T Cells help to amplify inflammatory responses induced by Salmonella enterica serotype typhimurium in the intestinal mucosa. Infect. Immun. 76, 2008-2017. doi: 10.1128/IAI.01691-07

Golubeva, Y. A., Ellermeier, J. R., Cott Chubiz, J. E., and Slauch, J. M. (2016). Intestinal long-chain fatty acids act as a direct signal to modulate expression of the Salmonella pathogenicity island 1 type III secretion system. mBio 7:e0217015. doi: $10.1128 / \mathrm{mBio} .02170-15$

Golubeva, Y. A., Sadik, A. Y., Ellermeier, J. R., and Slauch, J. M. (2012). Integrating global regulatory input into the Salmonella pathogenicity island 1 type III secretion system. Genetics 190, 79-90. doi: 10.1534/genetics.111.132779

Gonyar, L. A., and Kendall, M. M. (2014). Ethanolamine and choline promote expression of putative and characterized fimbriae in enterohemorrhagic Escherichia coli O157:H7. Infect. Immun. 82, 193-201. doi: 10.1128/IAI. 00980-13

Gopinath, S., Lichtman, J. S., Bouley, D. M., Elias, J. E., and Monack, D. M. (2014). Role of disease-associated tolerance in infectious superspreaders. Proc. Natl. Acad. Sci. U.S.A. 111, 15780-15785. doi: 10.1073/pnas.1409968111

Gordon, M. A. (2008). Salmonella infections in immunocompromised adults. J. Infect. 56, 413-422. doi: 10.1016/j.jinf.2008.03.012

Graham, S. M., Molyneux, E. M., Walsh, A. L., Cheesbrough, J. S., Molyneux, M. E., and Hart, C. A. (2000). Nontyphoidal Salmonella infections of children in tropical Africa. Pediatr. Infect. Dis. J. 19, 1189-1196. doi: 10.1097/00006454200012000-00016

Guignot, J., Caron, E., Beuzón, C., Bucci, C., Kagan, J., Roy, C., et al. (2004). Microtubule motors control membrane dynamics of Salmonella-containing vacuoles. J. Cell Sci. 117, 1033-1045. doi: 10.1242/jcs.00949

Günster, R. A., Matthews, S. A., Holden, D. W., and Thurston, T. L. M. (2017). SseK1 and SseK3 type III secretion system effectors inhibit NF-кB signaling and necroptotic cell death in Salmonella-infected macrophages. Infect. Immun. 85:e00010-17. doi: 10.1128/IAI.00010-17

Halang, P., Toulouse, C., Geißel, B., Michel, B., Flauger, B., Müller, M., et al. (2015). Response of Vibrio cholerae to the catecholamine hormones epinephrine and norepinephrine. J. Bacteriol. 197, 3769-3778. doi: 10.1128/JB. 00345-15

Hamer, H. M., Jonkers, D., Venema, K., Vanhoutvin, S., Troost, F. J., and Brummer, R.-J. (2008). Review article: the role of butyrate on colonic function. Aliment. Pharmacol. Ther. 27, 104-119. doi: 10.1111/j.1365-2036.2007.03562.x

Hammer, N. D., Cassat, J. E., Noto, M. J., Lojek, L. J., Chadha, A. D., Schmitz, J. E., et al. (2014). Inter- and intraspecies metabolite exchange promotes virulence of antibiotic-resistant Staphylococcus aureus. Cell Host Microbe 16, 531-537. doi: 10.1016/j.chom.2014.09.002

Hammer, N. D., Reniere, M. L., Cassat, J. E., Zhang, Y., Hirsch, A. O., Hood, M. I., et al. (2013). Two heme-dependent terminal oxidases power Staphylococcus aureus organ-specific colonization of the vertebrate host. mBio 4:e00241-13. doi: $10.1128 / \mathrm{mBio} .00241-13$

Hansen-Wester, I., Stecher, B., and Hensel, M. (2002). Type III secretion of Salmonella enterica serovar typhimurium translocated effectors and SseFG. Infect. Immun. 70, 1403-1409. doi: 10.1128/IAI.70.3.1403-1409.2002

Hardt, W.-D., Chen, L.-M., Schuebel, K. E., Bustelo, X. R., and Galán, J. E. (1998). S. typhimurium encodes an activator of Rho GTPases that induces membrane ruffling and nuclear responses in host cells. Cell 93, 815-826. doi: 10.1016/ S0092-8674(00)81442-7

Harris, J. C., Dupont, H. L., and Hornick, R. B. (1972). Fecal leukocytes in diarrheal illness. Ann. Intern. Med. 76, 697-703. doi: 10.7326/0003-4819-76-5-697 
Hébrard, M., Kröger, C., Srikumar, S., Colgan, A., Händler, K., and Hinton, J. C. D. (2012). sRNAs and the virulence of Salmonella enterica serovar typhimurium. RNA Biol. 9, 437-445. doi: 10.4161/rna.20480

Heinzen, R. A., Scidmore, M. A., Rockey, D. D., and Hackstadt, T. (1996). Differential interaction with endocytic and exocytic pathways distinguish parasitophorous vacuoles of Coxiella burnetii and Chlamydia trachomatis. Infect. Immun. 64, 796-809.

Helaine, S., Thompson, J. A., Watson, K. G., Liu, M., Boyle, C., and Holden, D. W. (2010). Dynamics of intracellular bacterial replication at the single cell level. Proc. Natl. Acad. Sci. U.S.A. 107, 3746-3751. doi: 10.1073/pnas.1000041107

Hensel, M., Shea, J. E., Gleeson, C., Jones, M. D., Dalton, E., and Holden, D. W. (1995). Simultaneous identification of bacterial virulence genes by negative selection. Science 269, 400-403. doi: 10.1126/science.7618105

Hicks, K. G., Delbecq, S. P., Sancho-Vaello, E., Blanc, M.-P., Dove, K. K., Prost, L. R., et al. (2015). Acidic pH and divalent cation sensing by PhoQ are dispensable for systemic salmonellae virulence. eLife 4:e06792. doi: 10.7554/ eLife.06792

Hood, R. D., Peterson, S. B., and Mougous, J. D. (2017). From striking out to striking gold: discovering that type VI secretion targets bacteria. Cell Host Microbe 21, 286-289. doi: 10.1016/j.chom.2017.02.001

Iwasaki, A., and Medzhitov, R. (2004). Toll-like receptor control of the adaptive immune responses. Nat. Immunol. 5, 987-995. doi: 10.1038/ni1112

Jackson, L. K., Nawabi, P., Hentea, C., Roark, E. A., and Haldar, K. (2008). The Salmonella virulence protein SifA is a G protein antagonist. Proc. Natl. Acad. Sci. U.S.A. 105, 14141-14146. doi: 10.1073/pnas.0801872105

Jorgensen, I., Zhang, Y., Krantz, B. A., and Miao, E. A. (2016). Pyroptosis triggers pore-induced intracellular traps (PITs) that capture bacteria and lead to their clearance by efferocytosis. J. Exp. Med. 213, 2113-2128. doi: 10.1084/jem. 20151613

Juricova, H., Videnska, P., Lukac, M., Faldynova, M., Babak, V., Havlickova, H., et al. (2013). Influence of Salmonella enterica serovar enteritidis infection on the development of the cecum microbiota in newly hatched chicks. Appl. Environ. Microbiol. 79, 745-747. doi: 10.1128/AEM.02628-12

Kabir, M. R., Hossain, M. A., Paul, S. K., Mahmud, C., Ahmad, S., Mahmud, N. U., et al. (2012). Enteropathogens associated with acute diarrhea in a tertiary hospital of Bangladesh. Mymensingh Med. J. 21, 618-623.

Kato, A., Latifi, T., and Groisman, E. A. (2003). Closing the loop: the PmrA/PmrB two-component system negatively controls expression of its posttranscriptional activator PmrD. Proc. Natl. Acad. Sci. U.S.A. 100, 4706-4711. doi: 10.1073/pnas. 0836837100

Kawai, K., Fujita, M., and Nakao, M. (1974). Lipid components of two different regions of an intestinal epithelial cell membrane of mouse. Biochim. Biophys. Acta 369, 222-233. doi: 10.1016/0005-2760(74)90253-7

Kawai, T., and Akira, S. (2010). The role of pattern-recognition receptors in innate immunity: update on toll-like receptors. Nat. Immunol. 11, 373-384. doi: $10.1038 /$ ni.1863

Kelly, C. J., Zheng, L., Campbell, E. L., Saeedi, B., Scholz, C. C., Bayless, A. J., et al. (2015). Crosstalk between microbiota-derived short-chain fatty acids and intestinal epithelial HIF augments tissue barrier function. Cell Host Microbe 17, 662-671. doi: 10.1016/j.chom.2015.03.005

Kendall, M. M., Gruber, C. C., Parker, C. T., and Sperandio, V. (2012). Ethanolamine controls expression of genes encoding components involved in interkingdom signaling and virulence in enterohemorrhagic Escherichia coli O157:H7. mBio 3:e0050-12. doi: 10.1128/mBio.00050-12

Kendall, M. M., and Sperandio, V. (2016). What a dinner party! Mechanisms and functions of interkingdom signaling in host-pathogen associations. $\mathrm{mBio}$ 7:e01748-15. doi: 10.1128/mBio.01748-15

Kim, C. C., and Falkow, S. (2004). Delineation of upstream signaling events in the Salmonella pathogenicity island 2 transcriptional activation pathway. J. Bacteriol. 186, 4694-4704. doi: 10.1128/JB.186.14.4694-4704.2004

Kozak, G. K., MacDonald, D., Landry, L., and Farber, J. M. (2013). Foodborne outbreaks in Canada linked to produce: 2001 through 2009. J. Food Prot. 76, 173-183. doi: 10.4315/0362-028X.JFP-12-126

Kroemer, G., Galluzzi, L., Vandenabeele, P., Abrams, J., Alnemri, E., Baehrecke, E., et al. (2009). Classification of cell death. Cell Death Differ. 16, 3-11. doi: 10.1038/ cdd.2008.150

Kröger, C., Colgan, A., Srikumar, S., Händler, K., Sivasankaran, S. K., Hammarlöf, D. L., et al. (2013). An infection-relevant transcriptomic compendium for
Salmonella enterica serovar typhimurium. Cell Host Microbe 14, 683-695. doi: 10.1016/j.chom.2013.11.010

Kröger, C., Dillon, S. C., Cameron, A. D. S., Papenfort, K., Sivasankaran, S. K., Hokamp, K., et al. (2012). The transcriptional landscape and small RNAs of Salmonella enterica serovar typhimurium. Proc. Natl. Acad. Sci. U.S.A. 109, E1277-E1286. doi: 10.1073/pnas.1201061109

Kühn, L. C. (2015). Iron regulatory proteins and their role in controlling iron metabolism. Metallomics 7, 232-243. doi: 10.1039/C4MT00164H

Lam, L. H., and Monack, D. M. (2014). Intraspecies competition for niches in the distal gut dictate transmission during persistent Salmonella infection. PLOS Pathog. 10:e1004527. doi: 10.1371/journal.ppat.1004527

Lara-Tejero, M., Sutterwala, F. S., Ogura, Y., Grant, E. P., Bertin, J., Coyle, A. J., et al. (2006). Role of the caspase-1 inflammasome in Salmonella typhimurium pathogenesis. J. Exp. Med. 203, 1407-1412. doi: 10.1084/jem.20060206

Lawhon, S. D., Maurer, R., Suyemoto, M., and Altier, C. (2002). Intestinal shortchain fatty acids alter Salmonella typhimurium invasion gene expression and virulence through BarA/SirA. Mol. Microbiol. 46, 1451-1464. doi: 10.1046/j. 1365-2958.2002.03268.x

Lawley, T. D., Bouley, D. M., Hoy, Y. E., Gerke, C., Relman, D. A., and Monack, D. M. (2008). Host transmission of Salmonella enterica serovar typhimurium is controlled by virulence factors and indigenous intestinal microbiota. Infect. Immun. 76, 403-416. doi: 10.1128/IAI.01189-07

Lee, C. A., and Falkow, S. (1990). The ability of Salmonella to enter mammalian cells is affected by bacterial growth state. Proc. Natl. Acad. Sci. U.S.A. 87, 4304-4308. doi: 10.1073/pnas.87.11.4304

Lee, E.-J., and Groisman, E. A. (2010). An antisense RNA that governs the expression kinetics of a multifunctional virulence gene. Mol. Microbiol. 76, 1020-1033. doi: 10.1111/j.1365-2958.2010.07161.x

Lee, E.-J., and Groisman, E. A. (2012). Control of a Salmonella virulence locus by an ATP-sensing leader mRNA. Nature 486, 271-275. doi: 10.1038/nature11090

Lindgren, S. W., Stojilikovic, I., and Heffron, F. (1996). Macrophage killing is an essential virulence mechanism of Salmonella typhimurium. Proc. Natl. Acad. Sci. U.S.A. 93, 4197-4201. doi: 10.1073/pnas.93.9.4197

Lipton, B. A., Davidson, E. P., Ginsberg, B. H., and Yorek, M. A. (1990). Ethanolamine metabolism in cultured bovine aortic endothelial cells. J. Biol. Chem. 265, 7195-7201.

Lipton, B. A., Yorek, M. A., and Ginsberg, B. H. (1988). Ethanolamine and choline transport in cultured bovine aortic endothelial cells. J. Cell. Physiol. 137, 571-576. doi: 10.1002/jcp.1041370325

Liss, V., Swart, A. L., Kehl, A., Hermanns, N., Zhang, Y., Chikkaballi, D., et al. (2017). Salmonella enterica remodels the host cell endosomal system for efficient intravacuolar nutrition. Cell Host Microbe 21, 390-402. doi: 10.1016/ j.chom.2017.02.005

Liu, J. Z., Jellbauer, S., Poe, A. J., Ton, V., Pesciaroli, M., Kehl-Fie, T. E., et al. (2012). Zinc sequestration by the neutrophil protein calprotectin enhances Salmonella growth in the inflamed gut. Cell Host Microbe 11, 227-239. doi: 10.1016/j.chom. 2012.01.017

Löber, S., Jäckel, D., Kaiser, N., and Hensel, M. (2006). Regulation of Salmonella pathogenicity island 2 genes by independent environmental signals. Int. J. Med. Microbiol. 296, 435-447. doi: 10.1016/j.ijmm.2006.05.001

Lopez, C. A., Rivera-Chávez, F., Byndloss, M. X., and Bäumler, A. J. (2015). The periplasmic nitrate reductase NapABC supports luminal growth of Salmonella enterica serovar typhimurium during colitis. Infect. Immun. 83, 3470-3478. doi: 10.1128/IAI.00351-15

Lopez, C. A., Winter, S. E., Rivera-Chávez, F., Xavier, M. N., Poon, V., Nuccio, S.-P., et al. (2012). Phage-mediated acquisition of a type III secreted effector protein boosts growth of Salmonella by nitrate respiration. mBio 3:e00143-12. doi: $10.1128 / \mathrm{mBio} .00143-12$

Louis, P., and Flint, H. J. (2009). Diversity, metabolism and microbial ecology of butyrate-producing bacteria from the human large intestine. FEMS Microbiol. Lett. 294, 1-8. doi: 10.1111/j.1574-6968.2009.01514.x

Luzader, D. H., Clark, D. E., Gonyar, L. A., and Kendall, M. M. (2013). EutR is a direct regulator of genes that contribute to metabolism and virulence in enterohemorrhagic Escherichia coli O157:H7. J. Bacteriol. 195, 4947-4953. doi: 10.1128/JB.00937-13

Ma, A. T., and Mekalanos, J. J. (2010). In vivo actin cross-linking induced by Vibrio cholerae type VI secretion system is associated with intestinal inflammation. Proc. Natl. Acad. Sci. U.S.A. 107, 4365-4370. doi: 10.1073/pnas.0915156107 
Maadani, A., Fox, K. A., Mylonakis, E., and Garsin, D. A. (2007). Enterococcus faecalis mutations affecting virulence in the Caenorhabditis elegans model host. Infect. Immun. 75, 2634-2637. doi: 10.1128/IAI.01372-06

Maier, L., Diard, M., Sellin, M. E., Chouffane, E.-S., Trautwein-Weidner, K., Periaswamy, B., et al. (2014). Granulocytes impose a tight bottleneck upon the gut luminal pathogen population during Salmonella typhimurium colitis. PLOS Pathog. 10:e1004557. doi: 10.1371/journal.ppat.1004557

Maier, L., Vyas, R., Cordova, C. D., Lindsay, H., Schmidt, T. S. B., Brugiroux, S., et al. (2013). Microbiota-derived hydrogen fuels Salmonella typhimurium invasion of the gut ecosystem. Cell Host Microbe 14, 641-651. doi: 10.1016/j. chom.2013.11.002

Man, S. M., Tourlomousis, P., Hopkins, L., Monie, T. P., Fitzgerald, K. A., and Bryant, C. E. (2013). Salmonella infection induces recruitment of caspase-8 to the inflammasome to modulate interleukin-1 $\beta$ production. J. Immunol. 191, 5239-5246. doi: 10.4049/jimmunol.1301581

Marteyn, B., West, N., Browning, D., Cole, J., Shaw, J., Palm, F., et al. (2010). Modulation of Shigella virulence in response to available oxygen in vivo. Nature 465, 355-358. doi: 10.1038/nature08970

Martin, L. B. (2012). Vaccines for typhoid fever and other salmonelloses. Curr. Opin. Infect. Dis. 25, 489-499. doi: 10.1097/QCO.0b013e328356ffeb

Mashruwala, A. A., Pang, Y. Y., Rosario-Cruz, Z., Chahal, H. K., Benson, M. A., Mike, L. A., et al. (2015). Nfu facilitates the maturation of iron-sulfur proteins and participates in virulence in Staphylococcus aureus. Mol. Microbiol. 95, 383-409. doi: 10.1111/mmi.12860

McKenney, E. S., Kendall, M. M., and Napier, B. (2016). Microbiota and pathogen 'pas de deux': setting up and breaking down barriers to intestinal infection. Pathog. Dis. 74:ftw051. doi: 10.1093/femspd/ftw051

McKenney, P. T., and Pamer, E. G. (2015). From hype to hope: the gut microbiota in enteric infectious disease. Cell 163, 1326-1332. doi: 10.1016/j.cell.2015.11.032

Medina, C. B., and Ravichandran, K. S. (2016). Do not let death do us part: 'find-me' signals in communication between dying cells and the phagocytes. Cell Death Differ. 23, 979-989. doi: 10.1038/cdd.2016.13

Mellin, J. R., Koutero, M., Dar, D., Nahori, M.-A., Sorek, R., and Cossart, P. (2014). Sequestration of a two-component response regulator by a riboswitch-regulated noncoding RNA. Science 345, 940-943. doi: 10.1126/science. 1255083

Miao, E. A., Alpuche-Aranda, C. M., Dors, M., Clark, A. E., Bader, M. W., Miller, S. I., et al. (2006). Cytoplasmic flagellin activates caspase-1 and secretion of interleukin $1 \beta$ via Ipaf. Nat. Immunol. 7, 569-575. doi: 10.1038/ ni1344

Miao, E. A., Leaf, I. A., Treuting, P. M., Mao, D. P., Dors, M., Sarkar, A., et al. (2010a). Caspase-1-induced pyroptosis is an innate immune effector mechanism against intracellular bacteria. Nat. Immunol. 11, 1136-1142. doi: 10.1038/ni.1960

Miao, E. A., Mao, D. P., Yudkovsky, N., Bonneau, R., Lorang, C. G., Warren, S. E., et al. (2010b). Innate immune detection of the type III secretion apparatus through the NLRC4 inflammasome. Proc. Natl. Acad. Sci. U.S.A. 107, 3076-3080. doi: 10.1073/pnas.0913087107

Miki, T., Goto, R., Fujimoto, M., Okada, N., and Hardt, W.-D. (2017). The bactericidal lectin RegIII $\beta$ prolongs gut colonization and enteropathy in the streptomycin mouse model for Salmonella diarrhea. Cell Host Microbe 21, 195-207. doi: 10.1016/j.chom.2016.12.008

Miki, T., Holst, O., and Hardt, W.-D. (2012). The bactericidal activity of the C-type lectin RegIII $\beta$ against gram-negative bacteria involves binding to lipid A. J. Biol. Chem. 287, 34844-34855. doi: 10.1074/jbc.M112.399998

Mizusaki, H., Takaya, A., Yamamoto, T., and Aizawa, S.-I. (2008). Signal pathway in salt-activated expression of the Salmonella pathogenicity island 1 type III secretion system in Salmonella enterica serovar typhimurium. J. Bacteriol. 190, 4624-4631. doi: 10.1128/JB.01957-07

Monack, D. M., Detweiler, C. S., and Falkow, S. (2001). Salmonella pathogenicity island 2-dependent macrophage death is mediated in part by the host cysteine protease caspase-1. Cell. Microbiol. 3, 825-837. doi: 10.1046/j.1462-5822.2001. 00162.x

Monack, D. M., Raupach, B., Hromockyj, A. E., and Falkow, S. (1996). Salmonella typhimurium invasion induces apoptosis in infected macrophages. Proc. Natl. Acad. Sci. U.S.A. 93, 9833-9838. doi: 10.1073/pnas.93.18.9833

Mooney, J. P., Lokken, K. L., Byndloss, M. X., George, M. D., Velazquez, E. M., Faber, F., et al. (2015). Inflammation-associated alterations to the intestinal microbiota reduce colonization resistance against non-typhoidal Salmonella during concurrent malaria parasite infection. Sci. Rep. 5:14603. doi: 10.1038/ srep 14603

Moreira, C. G., Russell, R., Mishra, A. A., Narayanan, S., Ritchie, J. M., Waldor, M. K., et al. (2016). Bacterial adrenergic sensors regulate virulence of enteric pathogens in the gut. mBio 7:e00826-16. doi: 10.1128/mBio.00826-16

Moreira, C. G., and Sperandio, V. (2012). Interplay between the QseC and QseE bacterial adrenergic sensor kinases in Salmonella enterica serovar typhimurium pathogenesis. Infect. Immun. 80, 4344-4353. doi: 10.1128/IAI.00803- 12

Moreira, C. G., Weinshenker, D., and Sperandio, V. (2010). QseC mediates Salmonella enterica serovar typhimurium virulence in vitro and in vivo. Infect. Immun. 78, 914-926. doi: 10.1128/IAI.01038-09

Mougous, J. D., Cuff, M. E., Raunser, S., Shen, A., Zhou, M., Gifford, C. A., et al. (2006). A virulence locus of Pseudomonas aeruginosa encodes a protein secretion apparatus. Science 312, 1526-1530. doi: 10.1126/science.1128393

Nairz, M., Ferring-Appel, D., Casarrubea, D., Sonnweber, T., Viatte, L., Schroll, A., et al. (2015a). Iron regulatory proteins mediate host resistance to Salmonella infection. Cell Host Microbe 18, 254-261. doi: 10.1016/j.chom.2015.06.017

Nairz, M., Schroll, A., Haschka, D., Dichtl, S., Sonnweber, T., Theurl, I., et al. (2015b). Lipocalin-2 ensures host defense against Salmonella typhimurium by controlling macrophage iron homeostasis and immune response. Eur. J. Immunol. 45, 3073-3086. doi: 10.1002/eji.201545569

Nairz, M., Fritsche, G., Crouch, M.-L. V., Barton, H. C., Fang, F. C., and Weiss, G. (2009). Slc1la1 limits intracellular growth of Salmonella enterica sv. Typhimurium by promoting macrophage immune effector functions and impairing bacterial iron acquisition. Cell. Microbiol. 11, 1365-1381. doi: 10.1111/j.1462-5822.2009.01337.x

Ng, K. M., Ferreyra, J. A., Higginbottom, S. K., Lynch, J. B., Kashyap, P. C., Gopinath, S., et al. (2013). Microbiota-liberated host sugars facilitate postantibiotic expansion of enteric pathogens. Nature 502, 96-99. doi: 10.1038/ nature 12503

Nikawa, J., Tsukagoshi, Y., and Yamashita, S. (1986). Cloning of a gene encoding choline transport in Saccharomyces cerevisiae. J. Bacteriol. 166, 328-330. doi: 10.1128/jb.166.1.328-330.1986

Núñez-Hernández, C., Tierrez, A., Ortega, Á. D., Pucciarelli, M. G., Godoy, M., Eisman, B., et al. (2013). Genome expression analysis of nonproliferating intracellular Salmonella enterica serovar typhimurium unravels an acid $\mathrm{pH}$ dependent PhoP-PhoQ response essential for dormancy. Infect. Immun. 81, 154-165. doi: 10.1128/IAI.01080-12

Ochman, H., Soncini, F. C., Solomon, F., and Groisman, E. A. (1996). Identification of a pathogenicity island required for Salmonella survival in host cells. Proc. Natl. Acad. Sci. U.S.A. 93, 7800-7804. doi: 10.1073/pnas.93.15.7800

Ohlson, M. B., Huang, Z., Alto, N. M., Blanc, M.-P., Dixon, J. E., Chai, J., et al. (2008). Structure and function of Salmonella SifA indicate that its interactions with SKIP, SseJ, and RhoA family GTPases induce endosomal tubulation. Cell Host Microbe 4, 434-446. doi: 10.1016/j.chom.2008.08.012

Olekhnovich, I. N., and Kadner, R. J. (2002). DNA-binding activities of the HilC and HilD virulence regulatory proteins of Salmonella enterica serovar typhimurium. J. Bacteriol. 184, 4148-4160. doi: 10.1128/JB.184.15.4148-4160. 2002

Osborne, S. E., and Coombes, B. K. (2011). Transcriptional priming of Salmonella pathogenicity island-2 precedes cellular invasion. PLOS ONE 6:e21648. doi: 10.1371/journal.pone.0021648

Owen, K. A., Anderson, C. J., and Casanova, J. E. (2016). Salmonella suppresses the TRIF-dependent type I interferon response in macrophages. mBio 7:e02051-15. doi: 10.1128/mBio.02051- 15

Owen, K. A., Meyer, C. B., Bouton, A. H., and Casanova, J. E. (2014). Activation of focal adhesion kinase by Salmonella suppresses autophagy via an Akt/mTOR signaling pathway and promotes bacterial survival in macrophages. PLOS Pathog. 10:e1004159. doi: 10.1371/journal.ppat.1004159

Palmer, L. D., and Skaar, E. P. (2016). Transition metals and virulence in bacteria. Annu. Rev. Genet. 50, 67-91. doi: 10.1146/annurev-genet-120215-035146

Pasparakis, M., and Vandenabeele, P. (2015). Necroptosis and its role in inflammation. Nature 517, 311-320. doi: 10.1038/nature14191

Phoebe Lostroh, C., and Lee, C. A. (2001). The Salmonella pathogenicity island1 type III secretion system. Microbes Infect. 3, 1281-1291. doi: 10.1016/S12864579(01)01488-5

Price-Carter, M., Tingey, J., Bobik, T. A., and Roth, J. R. (2001). The alternative electron acceptor tetrathionate supports B12-dependent anaerobic growth of 
Salmonella enterica serovar typhimurium on ethanolamine or 1,2-propanediol. J. Bacteriol. 183, 2463-2475. doi: 10.1128/JB.183.8.2463-2475.2001

Prost, L. R., Daley, M. E., Le Sage, V., Bader, M. W., Le Moual, H., Klevit, R. E., et al. (2007). Activation of the bacterial sensor kinase PhoQ by acidic pH. Mol. Cell 26, 165-174. doi: 10.1016/j.molcel.2007.03.008

Prouty, A. M., and Gunn, J. S. (2000). Salmonella enterica serovar typhimurium invasion is repressed in the presence of bile. Infect. Immun. 68, 6763-6769. doi: 10.1128/IAI.68.12.6763-6769.2000

Pukatzki, S., Ma, A. T., Sturtevant, D., Krastins, B., Sarracino, D., Nelson, W. C., et al. (2006). Identification of a conserved bacterial protein secretion system in Vibrio cholerae using the Dictyostelium host model system. Proc. Natl. Acad. Sci. U.S.A. 103, 1528-1533. doi: 10.1073/pnas.0510322103

Raffatellu, M., George, M. D., Akiyama, Y., Hornsby, M. J., Nuccio, S.-P., Paixao, T. A., et al. (2009). Lipocalin-2 resistance confers an advantage to Salmonella enterica serotype typhimurium for growth and survival in the inflamed intestine. Cell Host Microbe 5, 476-486. doi: 10.1016/j.chom.2009.03.011

Randle, C. L., Albro, P. W., and Dittmer, J. C. (1969). The phosphoglyceride composition of gram-negative bacteria and the changes in composition during growth. Biochim. Biophys. Acta 187, 214-220. doi: 10.1016/0005-2760(69) 90030-7

Rappl, C., Deiwick, J., and Hensel, M. (2003). Acidic pH is required for the functional assembly of the type III secretion system encoded by Salmonella pathogenicity island 2. FEMS Microbiol. Lett. 226, 363-372. doi: 10.1016/S03781097(03)00638-4

Rasko, D. A., Moreira, C. G., Li, D. R., Reading, N. C., Ritchie, J. M., Waldor, M. K., et al. (2008). Targeting QseC signaling and virulence for antibiotic development. Science 321, 1078-1080. doi: 10.1126/science. 1160354

Rathman, M., Sjaastad, M. D., and Falkow, S. (1996). Acidification of phagosomes containing Salmonella typhimurium in murine macrophages. Infect. Immun. 64, 2765-2773.

Rauch, I., Deets, K. A., Ji, D. X., von Moltke, J., Tenthorey, J. L., Lee, A. Y., et al. (2017). NAIP-NLRC4 inflammasomes coordinate intestinal epithelial cell expulsion with eicosanoid and IL-18 release via activation of caspase-1 and -8 . Immunity 46, 649-659. doi: 10.1016/j.immuni.2017.03.016

Raupach, B., Peuschel, S.-K., Monack, D. M., and Zychlinsky, A. (2006). Caspase1 -mediated activation of interleukin-1 $\beta$ (IL-1 $\beta$ ) and IL-18 contributes to innate immune defenses against Salmonella enterica serovar typhimurium infection. Infect. Immun. 74, 4922-4926. doi: 10.1128/IAI.00417-06

Rayamajhi, M., Zak, D. E., Chavarria-Smith, J., Vance, R. E., and Miao, E. A. (2013). Cutting edge: mouse NAIP1 detects the type III secretion system needle protein. J. Immunol. 191, 3986-3989. doi: 10.4049/jimmunol.1301549

Reading, N. C., Rasko, D. A., Torres, A. G., and Sperandio, V. (2009). The twocomponent system QseEF and the membrane protein QseG link adrenergic and stress sensing to bacterial pathogenesis. Proc. Natl. Acad. Sci. U.S.A. 106, 5889-5894. doi: 10.1073/pnas.0811409106

Rebuffat, S. (2012). Microcins in action: amazing defence strategies of enterobacteria. Biochem. Soc. Trans. 40, 1456-1462. doi: 10.1042/BST20120183

Rivera-Chávez, F., Lopez, C. A., Zhang, L. F., García-Pastor, L., Chávez-Arroyo, A., Lokken, K. L., et al. (2016a). Energy taxis toward host-derived nitrate supports a Salmonella pathogenicity island 1-independent mechanism of invasion. mBio 7:e00960-16. doi: 10.1128/mBio.00960-16

Rivera-Chávez, F., Zhang, L. F., Faber, F., Lopez, C. A., Byndloss, M. X., Olsan, E. E., et al. (2016b). Depletion of butyrate-producing Clostridia from the gut microbiota drives an aerobic luminal expansion of Salmonella. Cell Host Microbe 19, 443-454. doi: 10.1016/j.chom.2016.03.004

Rivera-Chavez, F., Winter, S. E., Lopez, C. A., Xavier, M. N., Winter, M. G., Nuccio, S.-P., et al. (2013). Salmonella uses energy taxis to benefit from intestinal inflammation. PLOS Pathog. 9:e1003267. doi: 10.1371/journal.ppat. 1003267

Robinson, N., McComb, S., Mulligan, R., Dudani, R., Krishnan, L., and Sad, S. (2012). Type I interferon induces necroptosis in macrophages during infection with Salmonella enterica serovar typhimurium. Nat. Immunol. 13, 954-962. doi: $10.1038 /$ ni.2397

Roof, D. M., and Roth, J. R. (1992). Autogenous regulation of ethanolamine utilization by a transcriptional activator of the eut operon in Salmonella typhimurium. J. Bacteriol. 174, 6634-6643. doi: 10.1128/jb.174.20.6634-66 43.1992
Rooks, M. G., Veiga, P., Reeves, A. Z., Lavoie, S., Yasuda, K., Asano, Y., et al. (2017). QseC inhibition as an antivirulence approach for colitis-associated bacteria. Proc. Natl. Acad. Sci. U.S.A. 114, 142-147. doi: 10.1073/pnas.1612836114

Russell, A. B., Wexler, A. G., Harding, B. N., Whitney, J. C., Bohn, A. J., Goo, Y. A., et al. (2014). A type VI secretion-related pathway in Bacteroidetes mediates interbacterial antagonism. Cell Host Microbe 16, 227-236. doi: 10.1016/j.chom. 2014.07.007

Sabag-Daigle, A., Blunk, H. M., Sengupta, A., Wu, J., Bogard, A. J., Ali, M. M., et al. (2016). A metabolic intermediate of the fructose-asparagine utilization pathway inhibits growth of a Salmonella FraB mutant. Sci. Rep. 6:28117. doi: $10.1038 /$ srep28117

Salcedo, S. P., Noursadeghi, M., Cohen, J., and Holden, D. W. (2001). Intracellular replication of Salmonella typhimurium strains in specific subsets of splenic macrophages in vivo. Cell. Microbiol. 3, 587-597. doi: 10.1046/j.1462-5822. 2001.00137.x

Sana, T. G., Flaugnatti, N., Lugo, K. A., Lam, L. H., Jacobson, A., Baylot, V., et al. (2016). Salmonella typhimurium utilizes a T6SS-mediated antibacterial weapon to establish in the host gut. Proc. Natl. Acad. Sci. U.S.A. 113, E5044-E5051. doi: 10.1073/pnas.1608858113

Sana, T. G., Lugo, K. A., and Monack, D. M. (2017). T6SS: the bacterial "fight club" in the host gut. PLOS Pathog. 13:e1006325. doi: 10.1371/journal.ppat.1006325

Sandra, A., and Cai, J. (1991). Plasma membrane appearance of phosphatidylethanolamine in stimulated macrophages. J. Leukoc. Biol. $50,19-27$.

Sassone-Corsi, M., Nuccio, S.-P., Liu, H., Hernandez, D., Vu, C. T., Takahashi, A. A., et al. (2016). Microcins mediate competition among Enterobacteriaceae in the inflamed gut. Nature 540, 280-283. doi: 10.1038/nature20557

Scallan, E., Hoekstra, R. M., Angulo, F. J., Tauxe, R. V., Widdowson, M.-A., Roy, S. L., et al. (2011). Foodborne illness acquired in the United States-major pathogens. Emerg. Infect. Dis. 17, 7-15. doi: 10.3201/eid1701.P11101

Schechter, L. M., and Lee, C. A. (2001). AraC/XylS family members, HilC and HilD, directly bind and derepress the Salmonella typhimurium hilA promoter. Mol. Microbiol. 40, 1289-1299. doi: 10.1046/j.1365-2958.2001.02462.x

Schwarz, S., Hood, R. D., and Mougous, J. D. (2010). What is type VI secretion doing in all those bugs? Trends Microbiol. 18, 531-537. doi: 10.1016/j.tim.2010. 09.001

Sekirov, I., Tam, N. M., Jogova, M., Robertson, M. L., Li, Y., Lupp, C., et al. (2008). Antibiotic-induced perturbations of the intestinal microbiota alter host susceptibility to enteric infection. Infect. Immun. 76, 4726-4736. doi: 10.1128/ IAI.00319-08

Sellin, M. E., Müller, A. A., Felmy, B., Dolowschiak, T., Diard, M., Tardivel, A., et al. (2014). Epithelium-intrinsic NAIP/NLRC4 inflammasome drives infected enterocyte expulsion to restrict Salmonella replication in the intestinal mucosa. Cell Host Microbe 16, 237-248. doi: 10.1016/j.chom.2014.07.001

Shea, J. E., Hensel, M., Gleeson, C., and Holden, D. W. (1996). Identification of a virulence locus encoding a second type III secretion system in Salmonella typhimurium. Proc. Natl. Acad. Sci. U.S.A. 93, 2593-2597. doi: 10.1073/pnas. 93.6.2593

Shiao, Y. J., and Vance, J. E. (1995). Evidence for an ethanolamine cycle: differential recycling of the ethanolamine moiety of phosphatidylethanolamine derived from phosphatidylserine and ethanolamine. Biochem. J. 310, 673-679. doi: $10.1042 / \mathrm{bj} 3100673$

Shotland, Y., Krämer, H., and Groisman, E. A. (2003). The Salmonella SpiC protein targets the mammalian Hook3 protein function to alter cellular trafficking. Mol. Microbiol. 49, 1565-1576. doi: 10.1046/j.1365-2958.2003.03668.x

Singh, R., Jamieson, A., and Cresswell, P. (2008). GILT is a critical host factor for Listeria monocytogenes infection. Nature 455, 1244-1247. doi: 10.1038/ nature 07344

Snoeck, V., Goddeeris, B., and Cox, E. (2005). The role of enterocytes in the intestinal barrier function and antigen uptake. Microbes Infect. 7, 997-1004. doi: 10.1016/j.micinf.2005.04.003

Soncini, F. C., García Véscovi, E., Solomon, F., and Groisman, E. A. (1996). Molecular basis of the magnesium deprivation response in Salmonella typhimurium: identification of PhoP-regulated genes. J. Bacteriol. 178, 5092-5099. doi: 10.1128/jb.178.17.5092-5099.1996

Spees, A. M., Wangdi, T., Lopez, C. A., Kingsbury, D. D., Xavier, M. N., Winter, S. E., et al. (2013). Streptomycin-induced inflammation enhances 
Escherichia coli gut colonization through nitrate respiration. mBio 4:e00430-13. doi: 10.1128/mBio.00430-13

Srikumar, S., Kröger, C., Hébrard, M., Colgan, A., Owen, S. V., Sivasankaran, S. K., et al. (2015). RNA-seq brings new insights to the intra-macrophage transcriptome of Salmonella typhimurium. PLOS Pathog. 11:e1005262. doi: 10.1371/journal.ppat.1005262

Stecher, B., Chaffron, S., Käppeli, R., Hapfelmeier, S., Freedrich, S., Weber, T. C., et al. (2010). Like will to like: abundances of closely related species can predict susceptibility to intestinal colonization by pathogenic and commensal bacteria. PLOS Pathog. 6:e1000711. doi: 10.1371/journal.ppat.1000711

Stecher, B., Robbiani, R., Walker, A. W., Westendorf, A. M., Barthel, M., Kremer, M., et al. (2007). Salmonella enterica serovar typhimurium exploits inflammation to compete with the intestinal microbiota. PLOS Biol. 5:e244. doi: 10.1371/journal.pbio.0050244

Steeb, B., Claudi, B., Burton, N. A., Tienz, P., Schmidt, A., Farhan, H., et al. (2013). Parallel exploitation of diverse host nutrients enhances Salmonella virulence. PLOS Pathog. 9:e1003301. doi: 10.1371/journal.ppat.1003301

Stein, M. A., Leung, K. Y., Zwick, M., Portillo, F. G., and Finlay, B. B. (1996). Identification of a Salmonella virulence gene required for formation of filamentous structures containing lysosomal membrane glycoproteins within epithelial cells. Mol. Microbiol. 20, 151-164. doi: 10.1111/j.1365-2958.1996. tb02497.x

Stelter, C., Käppeli, R., König, C., Krah, A., Hardt, W.-D., Stecher, B., et al. (2011). Salmonella-induced mucosal lectin RegIII $\beta$ kills competing gut microbiota. PLOS ONE 6:e20749. doi: 10.1371/journal.pone.0020749

Stewart, M. K., Cummings, L. A., Johnson, M. L., Berezow, A. B., and Cookson, B. T. (2011). Regulation of phenotypic heterogeneity permits Salmonella evasion of the host caspase-1 inflammatory response. Proc. Natl. Acad. Sci. U.S.A. 108, 20742-20747. doi: 10.1073/pnas. 1108963108

Stock, A. M., Robinson, V. L., and Goudreau, P. N. (2000). Two-component signal transduction. Annu. Rev. Biochem. 69, 183-215. doi: 10.1146/annurev.biochem. 69.1.183

Stojiljkovic, I., Bäumler, A. J., and Heffron, F. (1995). Ethanolamine utilization in Salmonella typhimurium: nucleotide sequence, protein expression, and mutational analysis of the $\operatorname{cch} \mathrm{A} \operatorname{cchB}$ eutE eutJ eutG eutH gene cluster. J. Bacteriol. 177, 1357-1366. doi: 10.1128/jb.177.5.1357-1366.1995

Strugnell, R. A., Scott, T. A., Wang, N., Yang, C., Peres, N., Bedoui, S., et al. (2014). Salmonella vaccines: lessons from the mouse model or bad teaching? Curr. Opin. Microbiol. 17, 99-105. doi: 10.1016/j.mib.2013.12.004

Sturgill-Koszycki, S., and Swanson, M. S. (2000). Legionella pneumophila replication vacuoles mature into acidic, endocytic organelles. J. Exp. Med. 192, 1261-1272. doi: 10.1084/jem.192.9.1261

Subashchandrabose, S., Hazen, T. H., Brumbaugh, A. R., Himpsl, S. D., Smith, S. N., Ernst, R. D., et al. (2014). Host-specific induction of Escherichia coli fitness genes during human urinary tract infection. Proc. Natl. Acad. Sci. U.S.A. 111, 18327-18332. doi: 10.1073/pnas.1415959112

Thiemann, S., Smit, N., Roy, U., Lesker, T. R., Gálvez, E. J. C., Helmecke, J., et al. (2017). Enhancement of IFN $\gamma$ production by distinct commensals ameliorates Salmonella-induced disease. Cell Host Microbe 21, 682.e5-694.e5. doi: 10.1016/ j.chom.2017.05.005

Thiennimitr, P., Winter, S. E., Winter, M. G., Xavier, M. N., Tolstikov, V., Huseby, D. L., et al. (2011). Intestinal inflammation allows Salmonella to use ethanolamine to compete with the microbiota. Proc. Natl. Acad. Sci. U.S.A. 108, 17480-17485. doi: 10.1073/pnas.1107857108

Tsolis, R. M., Adams, L. G., Ficht, T. A., and Bäumler, A. J. (1999). Contribution of Salmonella typhimurium virulence factors to diarrheal disease in calves. Infect. Immun. 67, 4879-4885.

Tubbs, A. L., Liu, B., Rogers, T. D., Sartor, R. B., and Miao, E. A. (2017). Dietary salt exacerbates experimental colitis. J. Immunol. 199, 1051-1059. doi: 10.4049/ jimmunol.1700356

Uchiya, K., Barbieri, M. A., Funato, K., Shah, A. H., Stahl, P. D., and Groisman, E. A. (1999). A Salmonella virulence protein that inhibits cellular trafficking. EMBO J. 18, 3924-3933. doi: 10.1093/emboj/18.14.3924

Vaishnava, S., Behrendt, C. L., Ismail, A. S., Eckmann, L., and Hooper, L. V. (2008). Paneth cells directly sense gut commensals and maintain homeostasis at the intestinal host-microbial interface. Proc. Natl. Acad. Sci. U.S.A. 105, 20858-20863. doi: 10.1073/pnas.0808723105
Valdivia, R. H., and Falkow, S. (1997). Fluorescence-based isolation of bacterial genes expressed within host cells. Science 277, 2007-2011. doi: 10.1126/science. 277.5334 .2007

van der Velden, A. W. M., Lindgren, S. W., Worley, M. J., and Heffron, F. (2000). Salmonella pathogenicity island 1-independent induction of apoptosis in infected macrophages by Salmonella enterica serotype typhimurium. Infect. Immun. 68, 5702-5709. doi: 10.1128/IAI.68.10.5702-5709.2000

van der Velden, A. W. M., Velasquez, M., and Starnbach, M. N. (2003). Salmonella rapidly kill dendritic cells via a caspase-1- dependent mechanism. J. Immunol. 171, 6742-6749. doi: 10.4049/jimmunol.171.12.6742

Vandal, O. H., Pierini, L. M., Schnappinger, D., Nathan, C. F., and Ehrt, S. (2008). A membrane protein preserves intrabacterial $\mathrm{pH}$ in intraphagosomal Mycobacterium tuberculosis. Nat. Med. 14, 849-854. doi: 10.1038/nm.1795

Vazquez-Torres, A., Jones-Carson, J., Bäumler, A. J., Falkow, S., Valdivia, R., Brown, W., et al. (1999). Extraintestinal dissemination of Salmonella by Cd18expressing phagocytes. Nature 401, 804-808. doi: 10.1038/44593

Vital, M., Howe, A. C., and Tiedje, J. M. (2014). Revealing the bacterial butyrate synthesis pathways by analyzing (Meta)genomic Data. mBio 5:e00889-14. doi: 10.1128/mBio.00889-14

Vojdani, J. D., Beuchat, L. R., and Tauxe, R. V. (2008). Juice-associated outbreaks of human illness in the United States, 1995 through 2005. J. Food Prot. 71, 356-364. doi: 10.4315/0362-028X-71.2.356

Weiss, D. S., Raupach, B., Takeda, K., Akira, S., and Zychlinsky, A. (2004). Toll-like receptors are temporally involved in host defense. J. Immunol. 172, 4463-4469. doi: 10.4049/jimmunol.172.7.4463

Westermann, A. J., Förstner, K. U., Amman, F., Barquist, L., Chao, Y., Schulte, L. N., et al. (2016). Dual RNA-Seq unveils noncoding RNA functions in host-pathogen interactions. Nature 529, 496-501. doi: 10.1038/nature16547

Wiles, S., Pickard, K. M., Peng, K., MacDonald, T. T., and Frankel, G. (2006). In vivo bioluminescence imaging of the murine pathogen Citrobacter rodentium. Infect. Immun. 74, 5391-5396. doi: 10.1128/IAI.00848-06

Winter, S. E., Thiennimitr, P., Winter, M. G., Butler, B. P., Huseby, D. L., Crawford, R. W., et al. (2010). Gut inflammation provides a respiratory electron acceptor for Salmonella. Nature 467, 426-429. doi: 10.1038/nature09415

Winter, S. E., Winter, M. G., Xavier, M. N., Thiennimitr, P., Poon, V., Keestra, A. M., et al. (2013). Host-derived nitrate boosts growth of E. coli in the inflamed gut. Science 339, 708-711. doi: 10.1126/science. 1232467

Wiström, J., Jertborn, M., Ekwall, E., Norlin, K., Söderquist, B., Strömberg, A., et al. (1992). Empiric treatment of acute diarrheal disease with norfloxacin. A randomized, placebo-controlled study. Swedish study group. Ann. Intern. Med. 117, 202-208. doi: 10.7326/0003-4819-117-3-202

Wösten, M. M., Kox, L. F., Chamnongpol, S., Soncini, F. C., and Groisman, E. A. (2000). A signal transduction system that responds to extracellular iron. Cell 103, 113-125. doi: 10.1016/S0092-8674(00)00092-1

Yang, J., Zhao, Y., Shi, J., and Shao, F. (2013). Human NAIP and mouse NAIP1 recognize bacterial type III secretion needle protein for inflammasome activation. Proc. Natl. Acad. Sci. U.S.A. 110, 14408-14413. doi: 10.1073/pnas. 1306376110

Yoon, H., McDermott, J. E., Porwollik, S., McClelland, M., and Heffron, F. (2009). Coordinated regulation of virulence during systemic infection of Salmonella enterica serovar typhimurium. PLOS Pathog. 5:e1000306. doi: 10.1371/journal. ppat.1000306

Yurist-Doutsch, S., Arrieta, M.-C., Vogt, S. L., and Finlay, B. B. (2014). Gastrointestinal microbiota-mediated control of enteric pathogens. Annu. Rev. Genet. 48, 361-382. doi: 10.1146/annurev-genet-120213-092421

Zaharik, M. L., Vallance, B. A., Puente, J. L., Gros, P., and Finlay, B. B. (2002). Host-pathogen interactions: host resistance factor nramp1 up-regulates the expression of Salmonella pathogenicity island-2 virulence genes. Proc. Natl. Acad. Sci. U.S.A. 99, 15705-15710. doi: 10.1073/pnas.252415599

Zeng, M. Y., Inohara, N., and Nuñez, G. (2017). Mechanisms of inflammationdriven bacterial dysbiosis in the gut. Mucosal Immunol. 10, 18-26. doi: 10.1038/ mi.2016.75

Zhao, Y., Yang, J., Shi, J., Gong, Y.-N., Lu, Q., Xu, H., et al. (2011). The NLRC4 inflammasome receptors for bacterial flagellin and type III secretion apparatus. Nature 477, 596-600. doi: 10.1038/nature 10510

Zimbler, D. L., Park, T. M., Arivett, B. A., Penwell, W. F., Greer, S. M., Woodruff, T. M., et al. (2012). Stress response and virulence functions of the Acinetobacter 
baumannii NfuA Fe-S scaffold protein. J. Bacteriol. 194, 2884-2893. doi: $10.1128 /$ JB.00213-12

Conflict of Interest Statement: The authors declare that the research was conducted in the absence of any commercial or financial relationships that could be construed as a potential conflict of interest.
Copyright (C) 2017 Anderson and Kendall. This is an open-access article distributed under the terms of the Creative Commons Attribution License (CC BY). The use, distribution or reproduction in other forums is permitted, provided the original author(s) or licensor are credited and that the original publication in this journal is cited, in accordance with accepted academic practice. No use, distribution or reproduction is permitted which does not comply with these terms. 